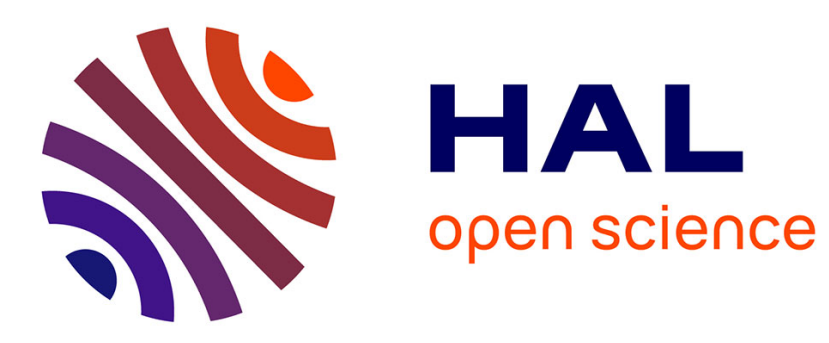

\title{
Characterization of a Cell-Assembled extracellular Matrix and the effect of the devitalization process
}

Laure Magnan, Gaëlle Labrunie, Sébastien Marais, Sylvie Rey, Nathalie

Dusserre, Marc Bonneu, Sabrina Lacomme, Etienne Gontier, Nicolas

L'Heureux

\section{To cite this version:}

Laure Magnan, Gaëlle Labrunie, Sébastien Marais, Sylvie Rey, Nathalie Dusserre, et al.. Characterization of a Cell-Assembled extracellular Matrix and the effect of the devitalization process. Acta Biomaterialia, 2018, 82, pp.56-67. 10.1016/j.actbio.2018.10.006 . inserm-03325188

\section{HAL Id: inserm-03325188 https://www.hal.inserm.fr/inserm-03325188}

Submitted on 24 Aug 2021

HAL is a multi-disciplinary open access archive for the deposit and dissemination of scientific research documents, whether they are published or not. The documents may come from teaching and research institutions in France or abroad, or from public or private research centers.
L'archive ouverte pluridisciplinaire HAL, est destinée au dépôt et à la diffusion de documents scientifiques de niveau recherche, publiés ou non, émanant des établissements d'enseignement et de recherche français ou étrangers, des laboratoires publics ou privés. 

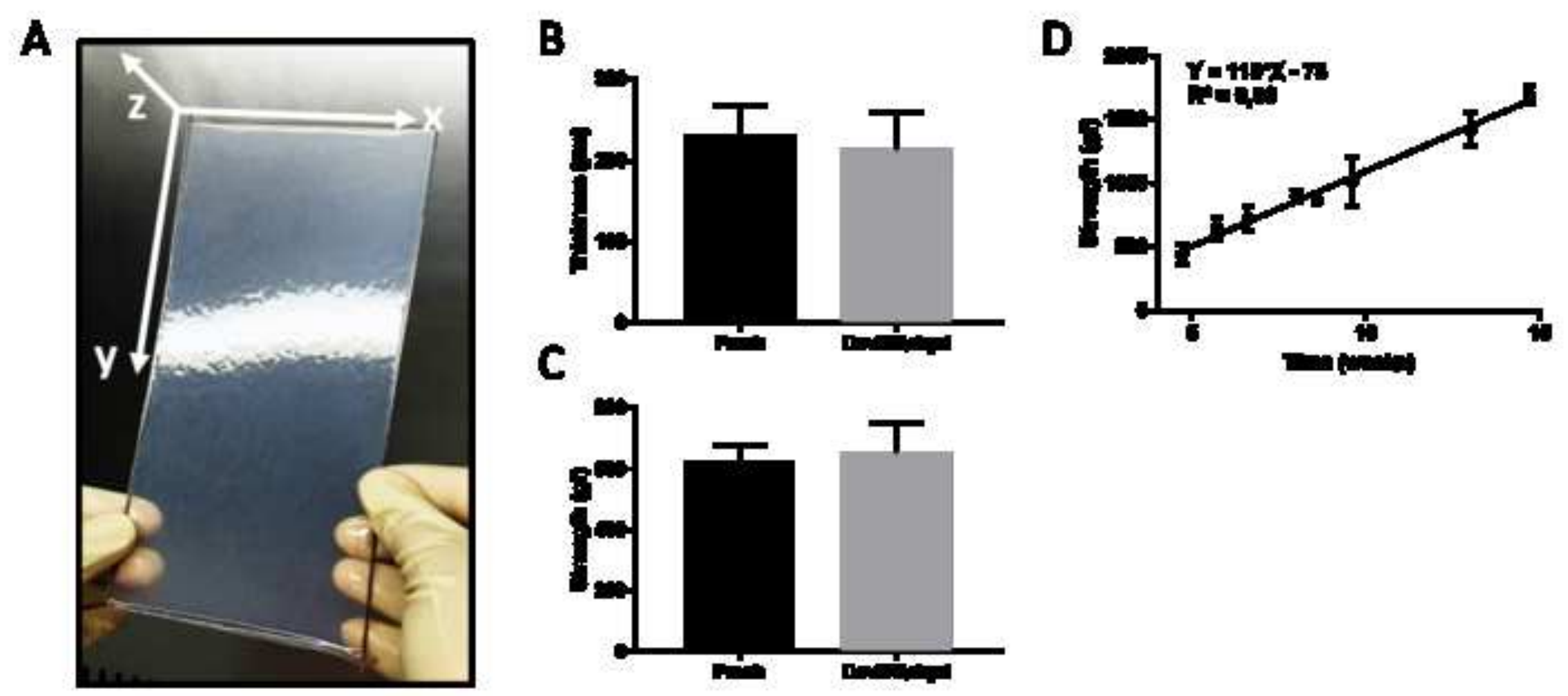


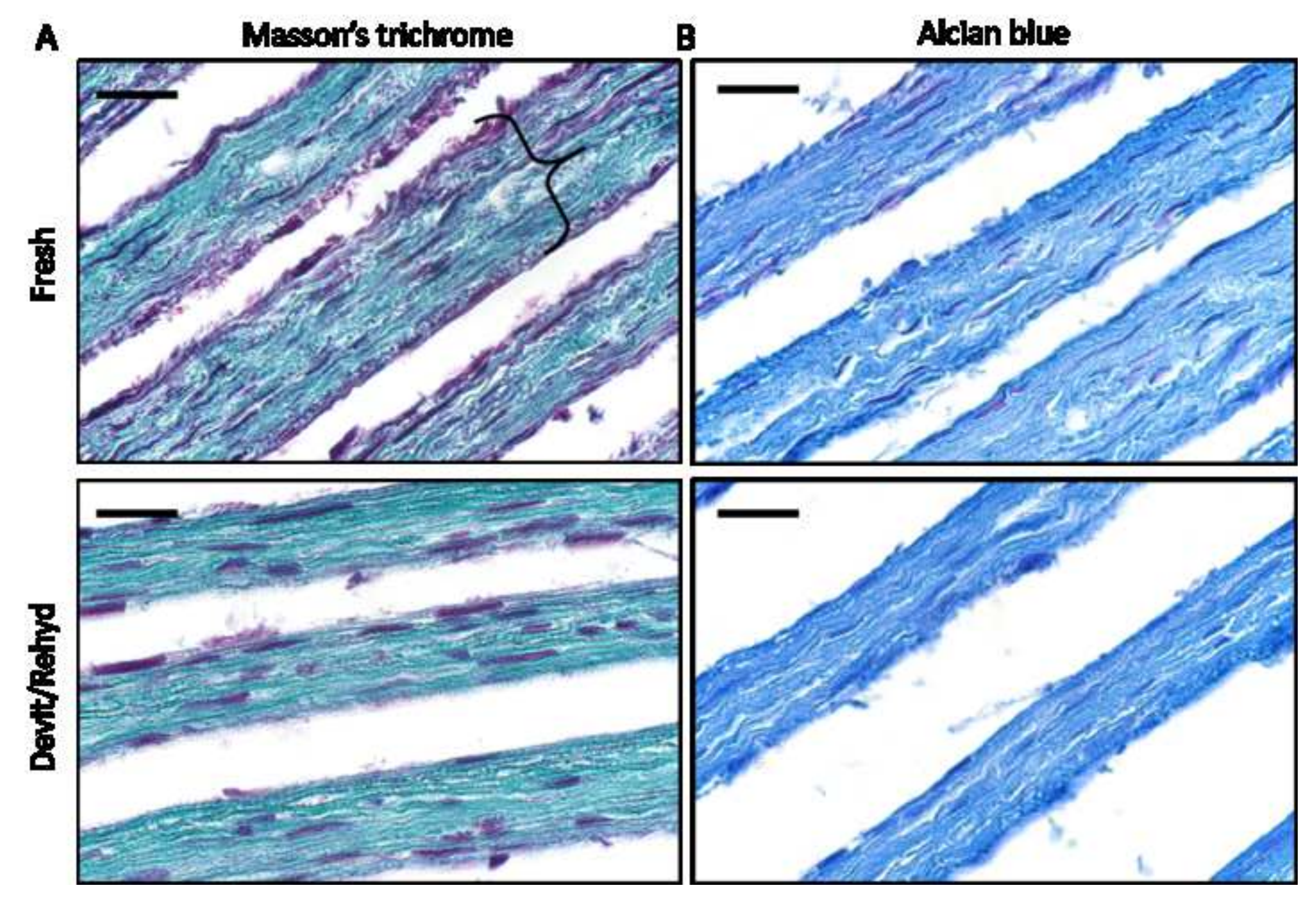

B Alclan blue
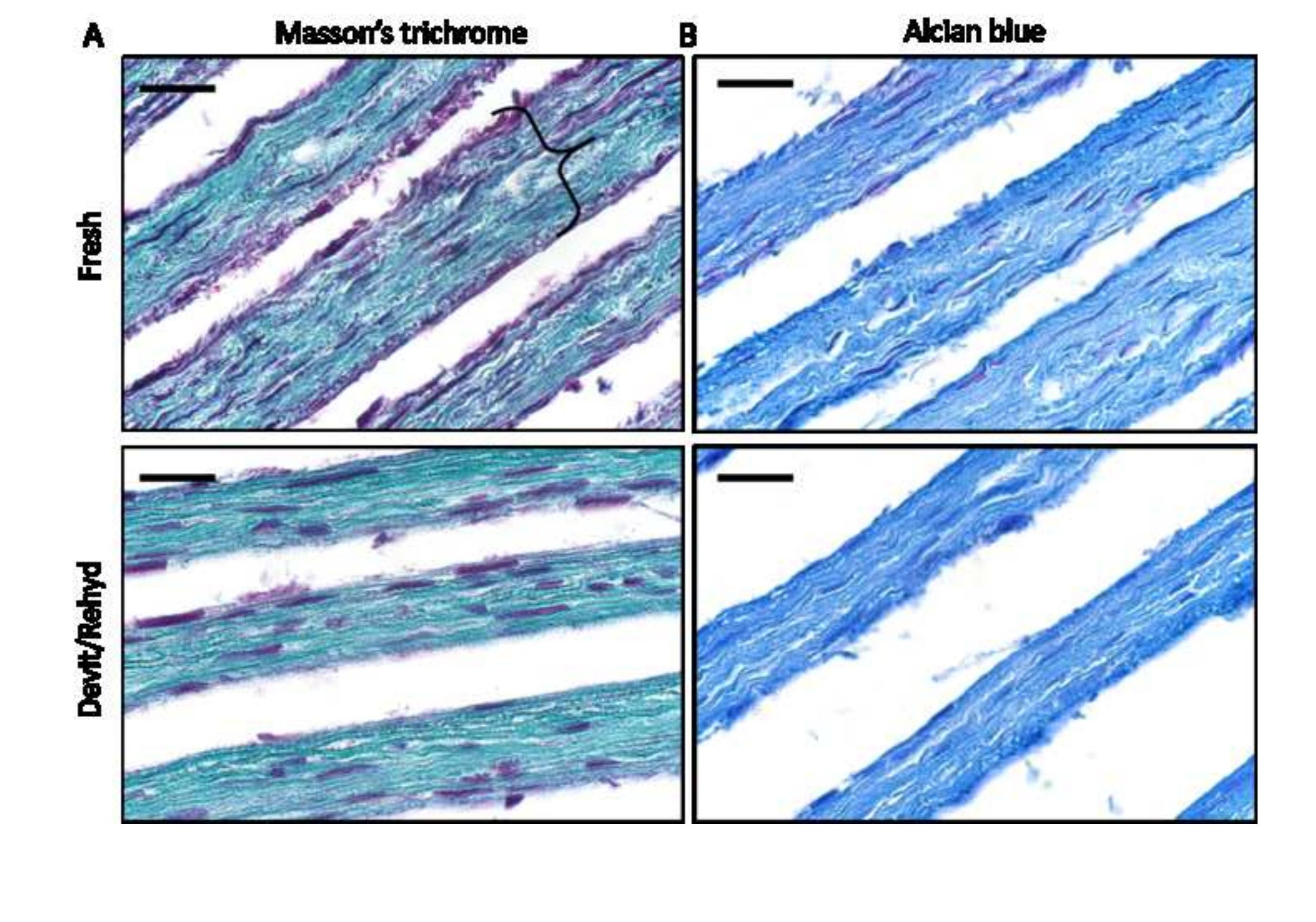
Click here to download high resolution image

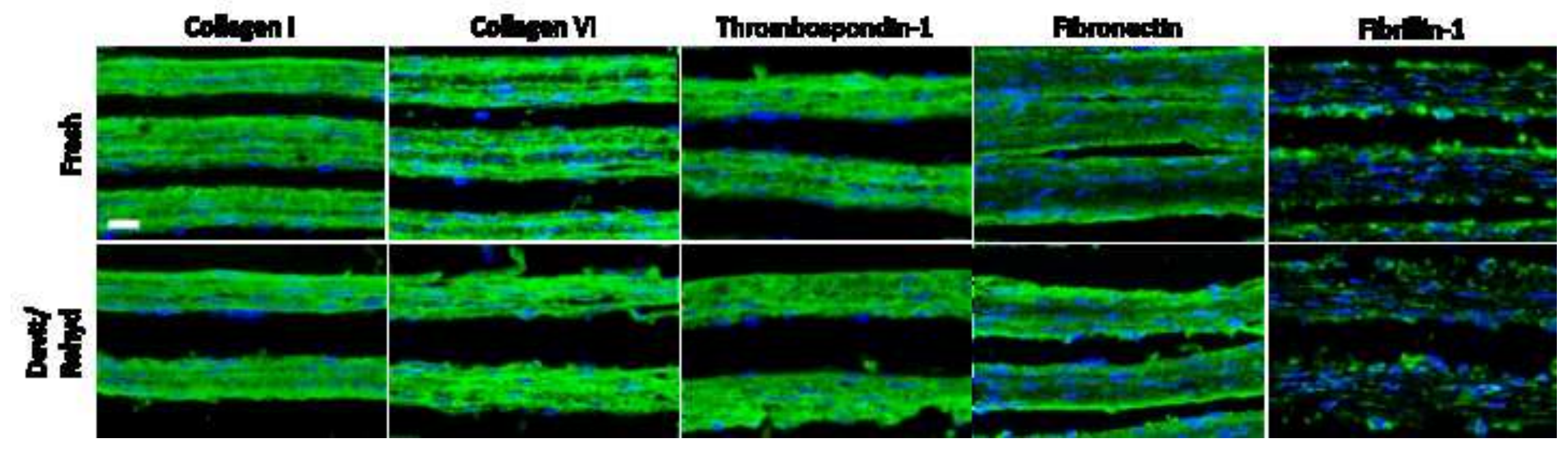


Click here to download high resolution image
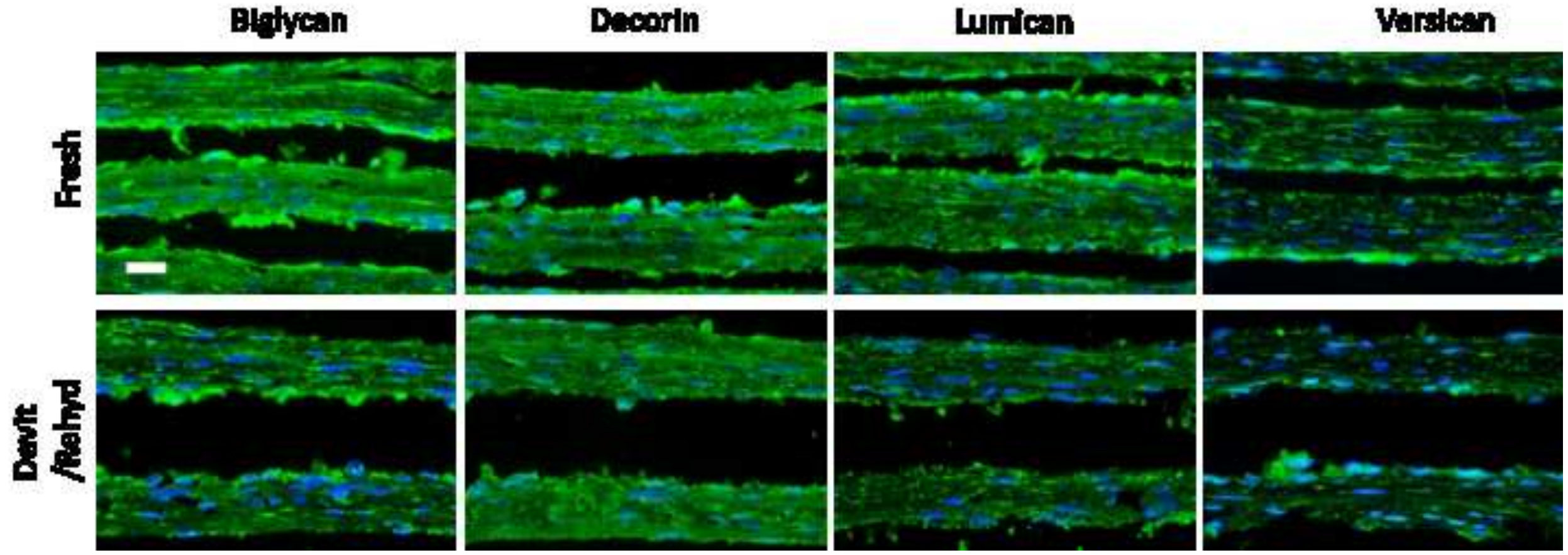
Click here to download high resolution image
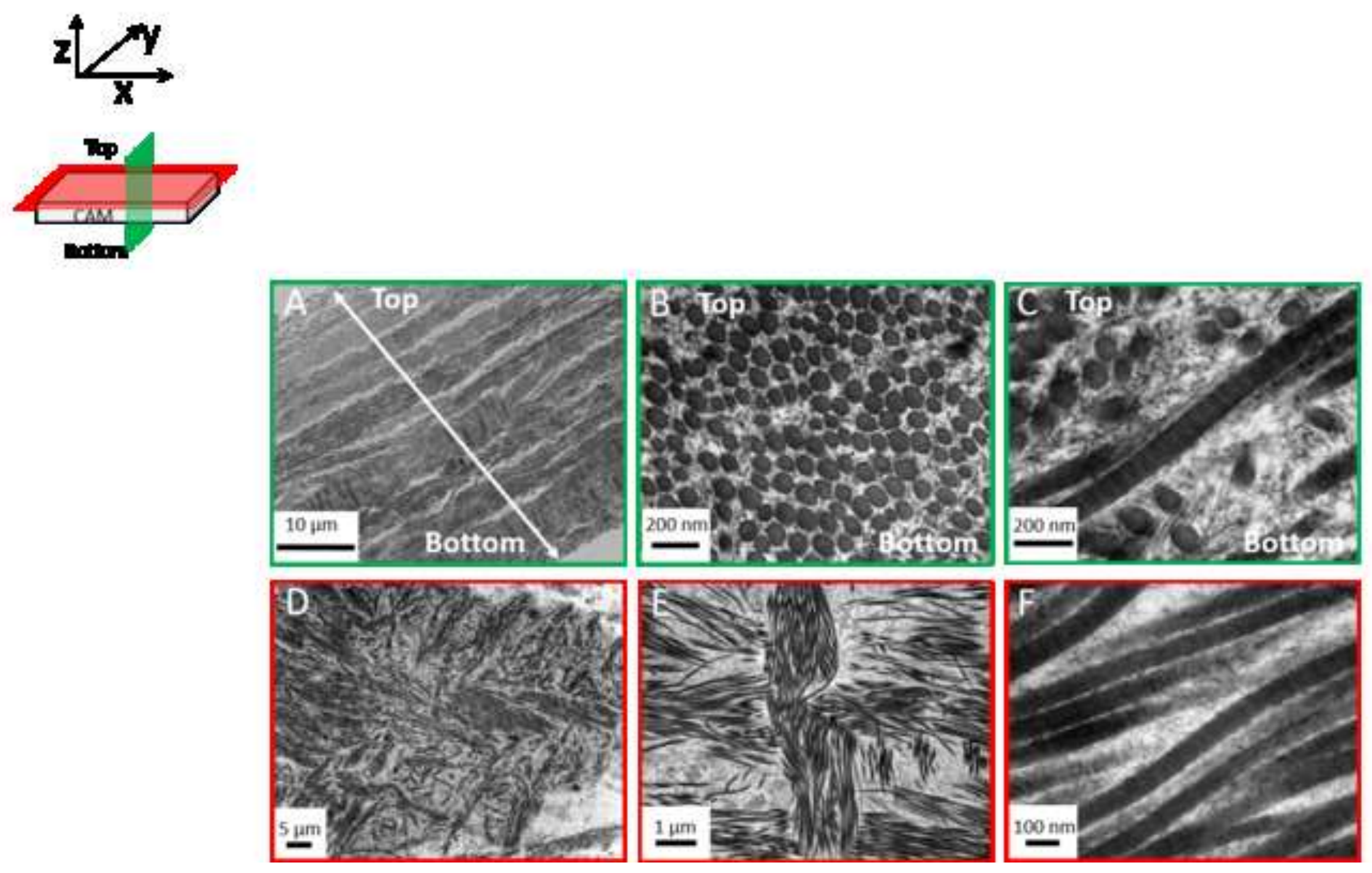

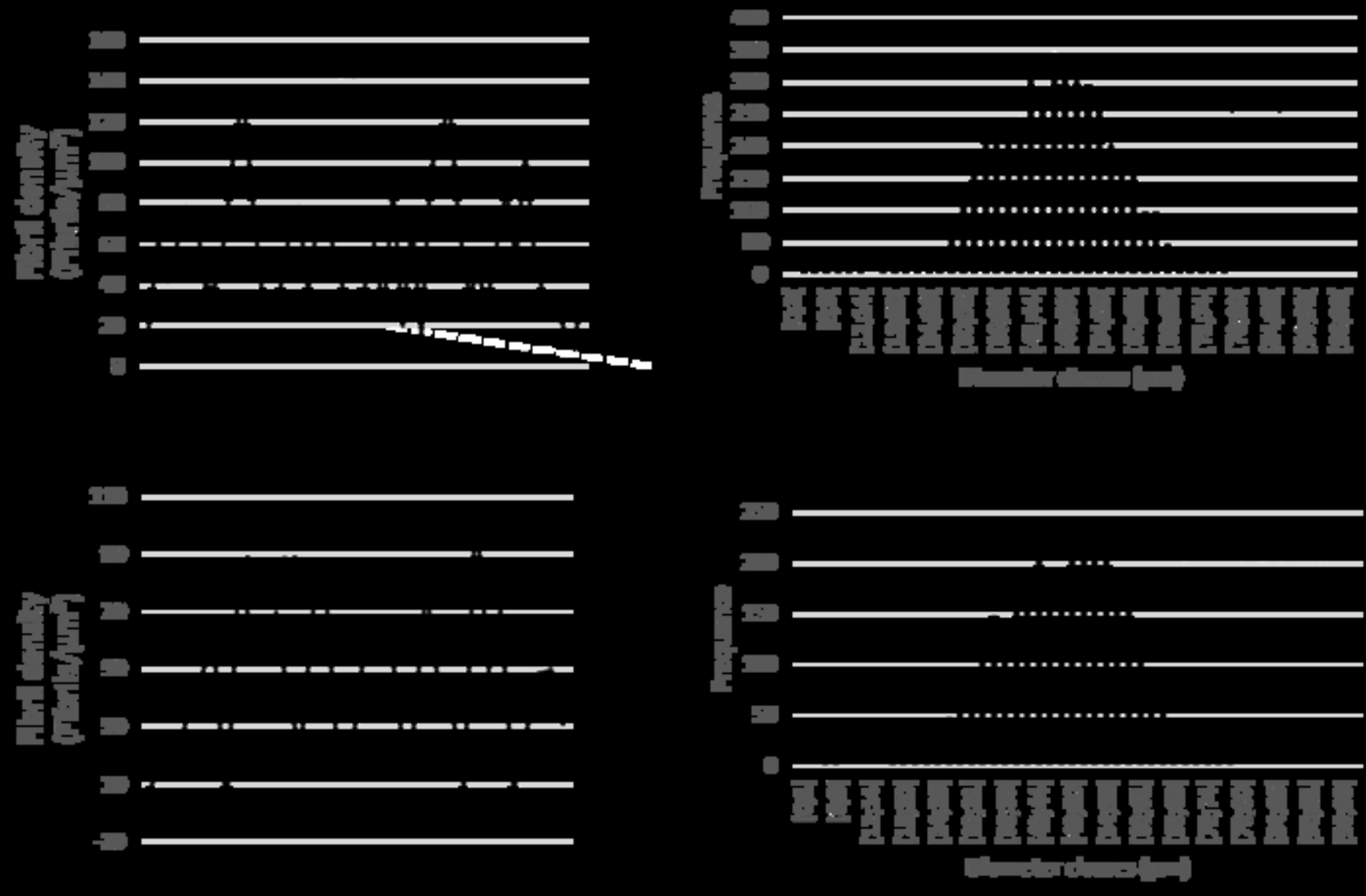
Click here to download high resolution image

A
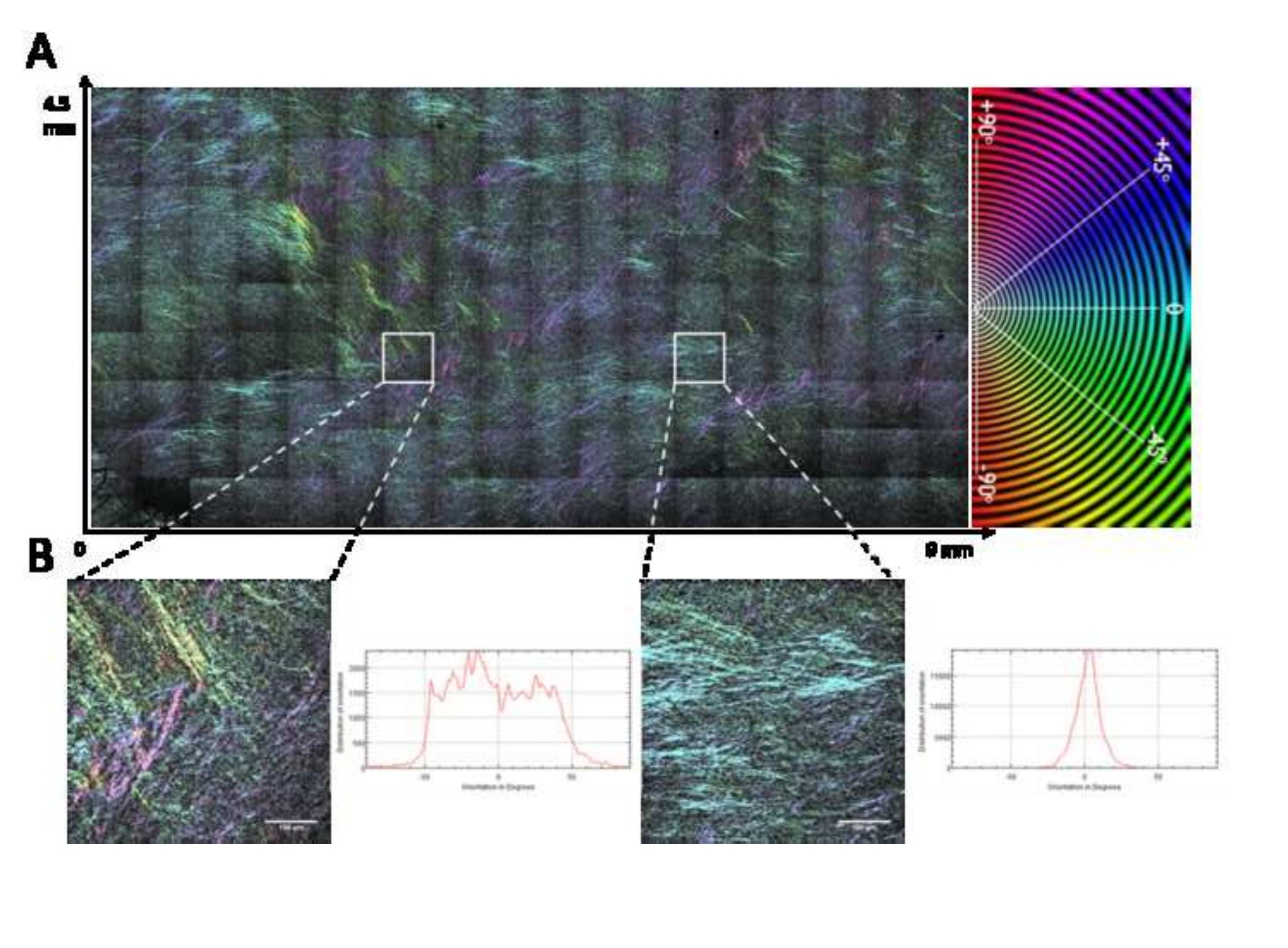
Click here to download high resolution image

A

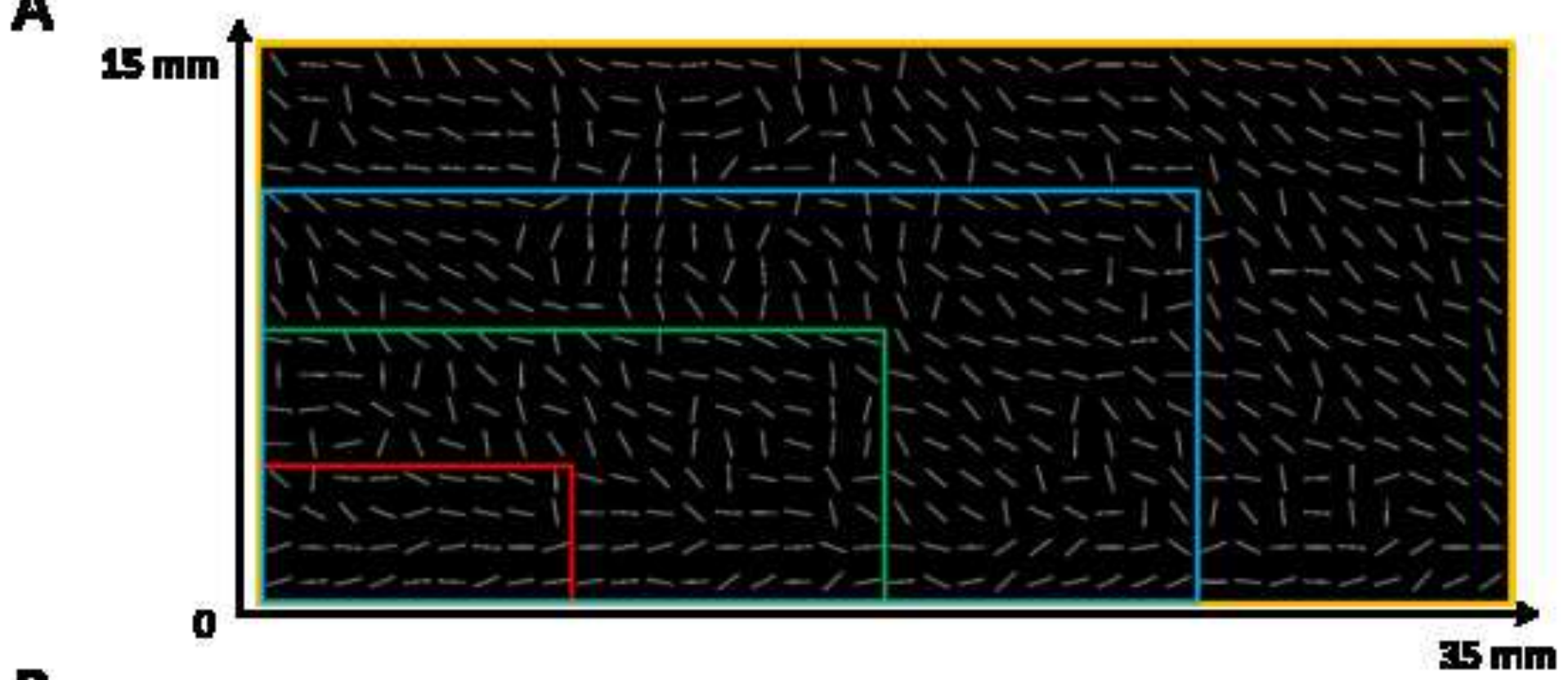

B

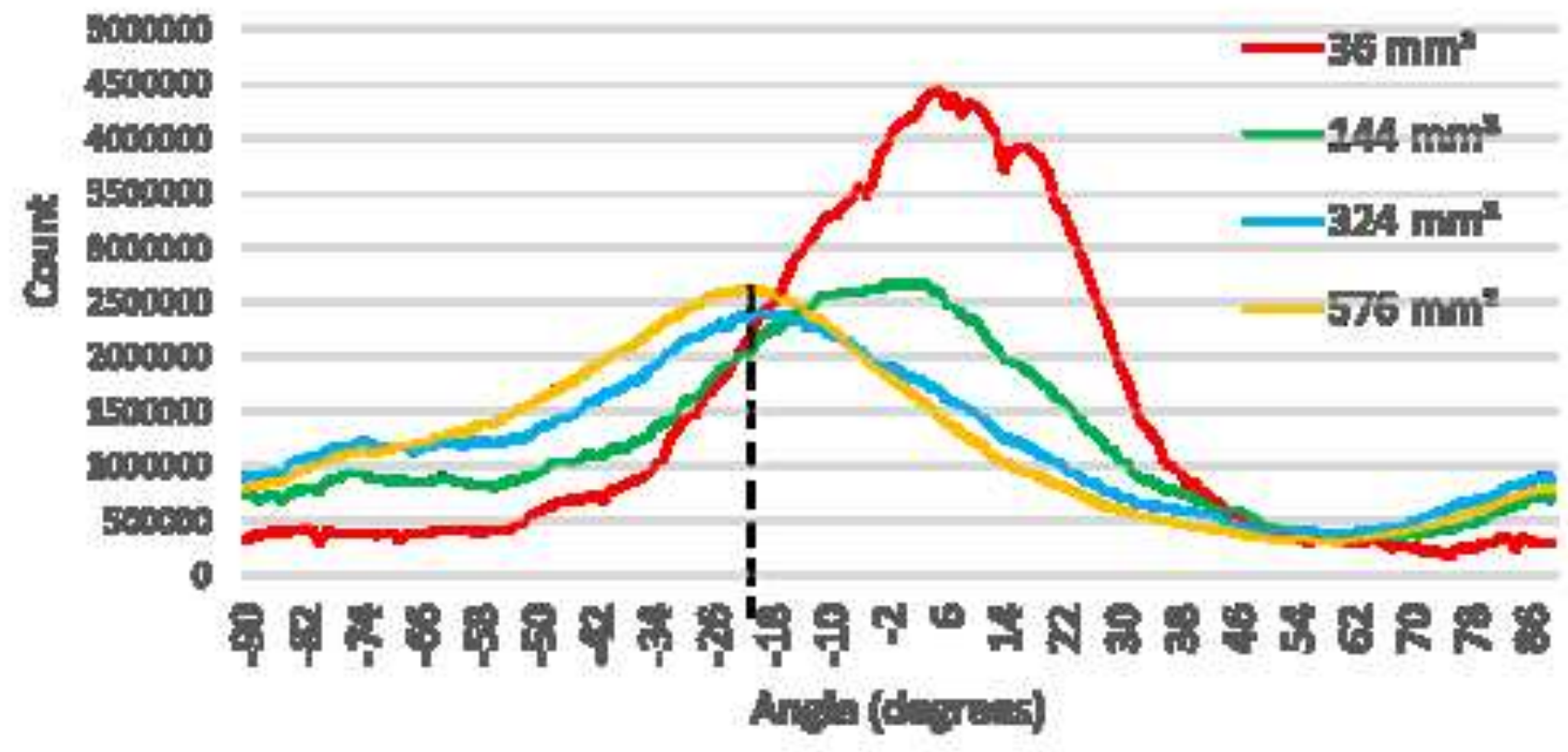


Click here to download high resolution image

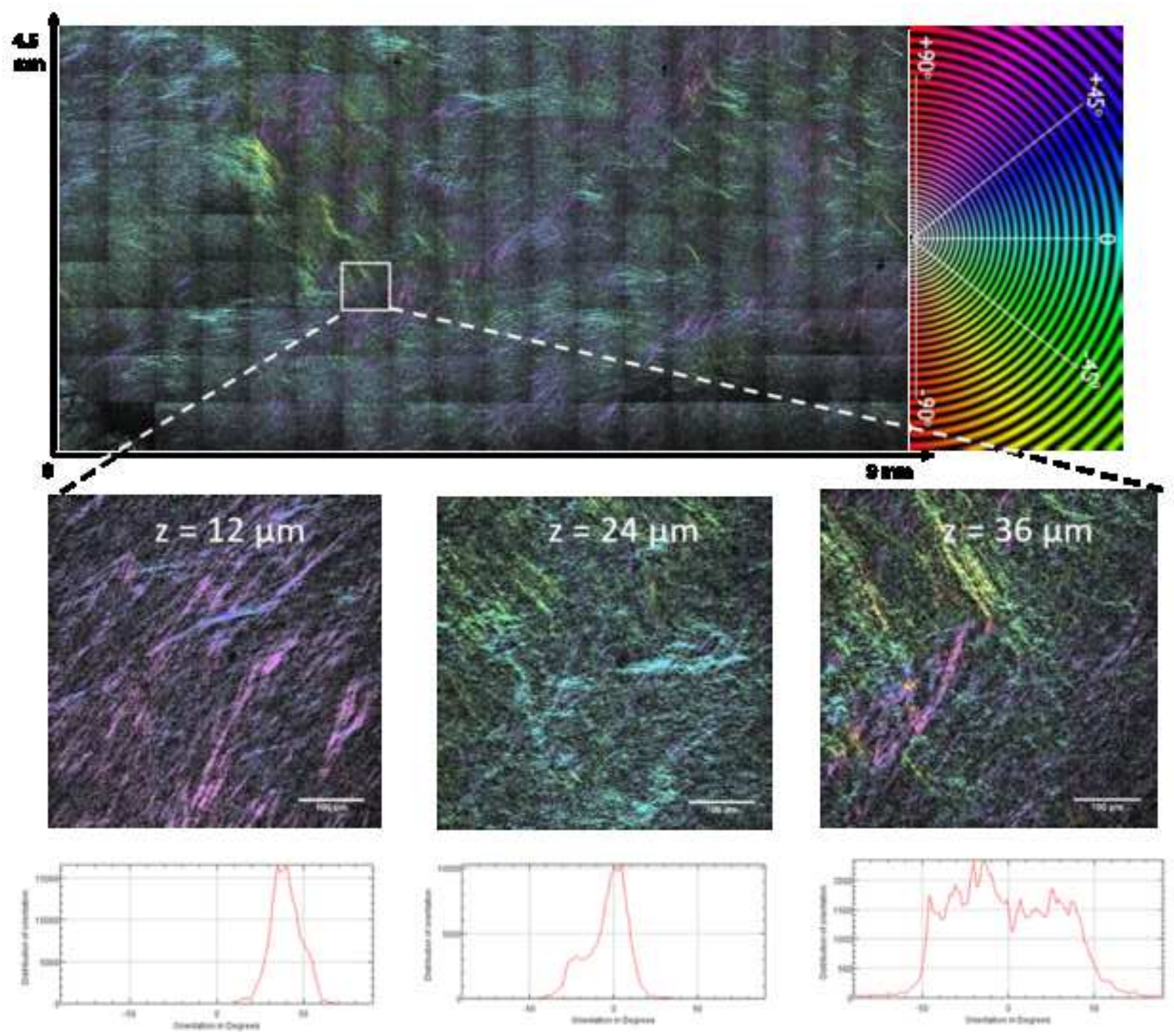


Table 1

Click here to download high resolution image

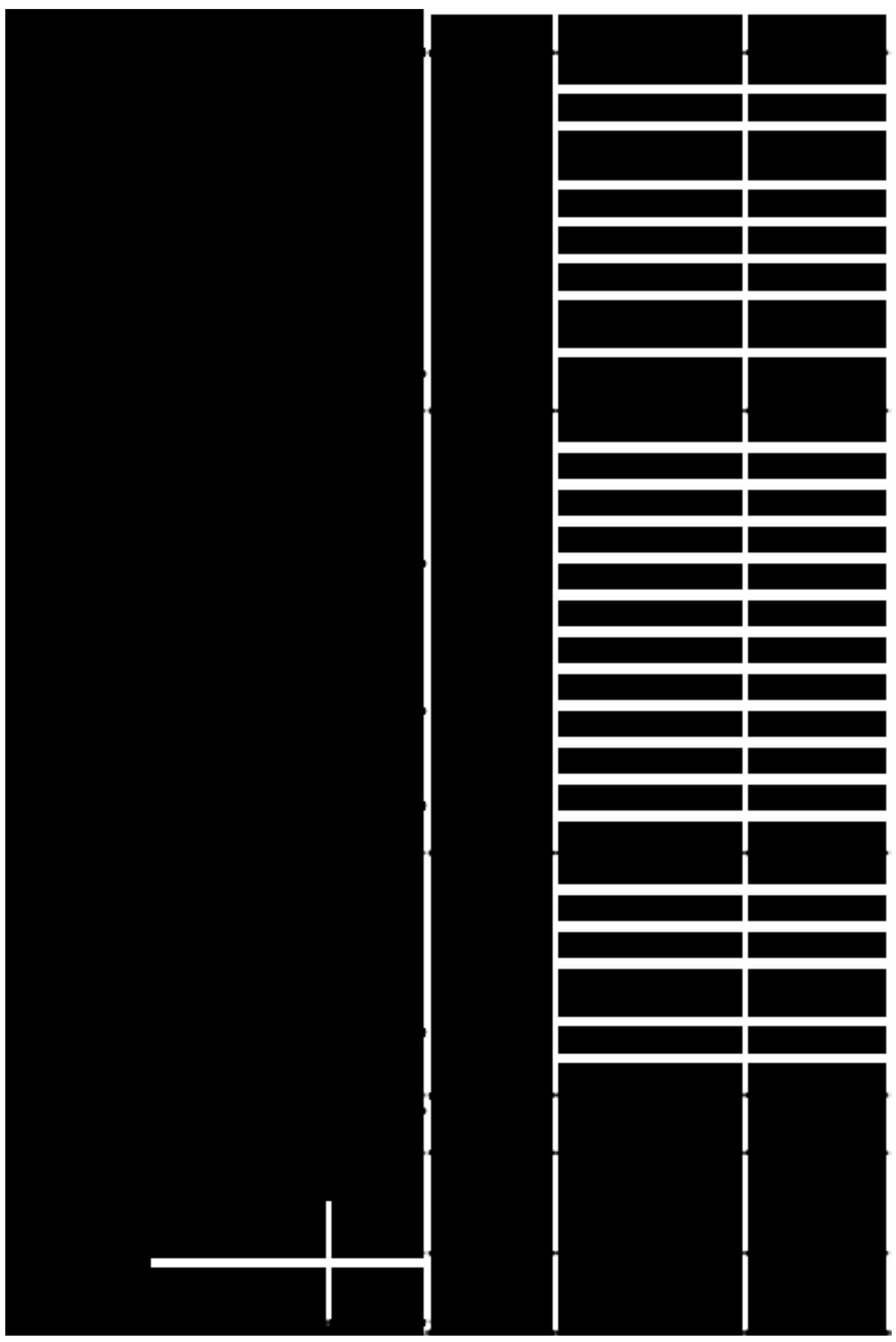


Supplemental figure
Click here to downlo

Click here to download Supplementary Material: Supplemental figure.tif

Click here to download Supplementary Material: Supplemental figure.tif

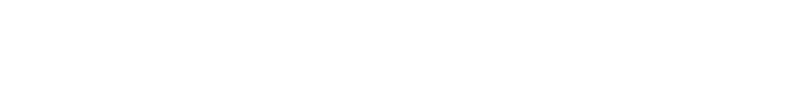

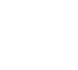
(1)

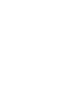
.

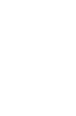

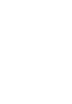

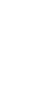

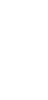
. . . .

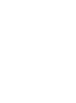
.

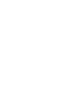

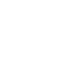

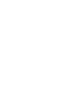

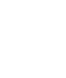

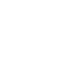

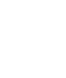

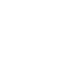

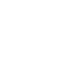

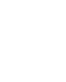

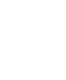

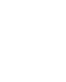
. 

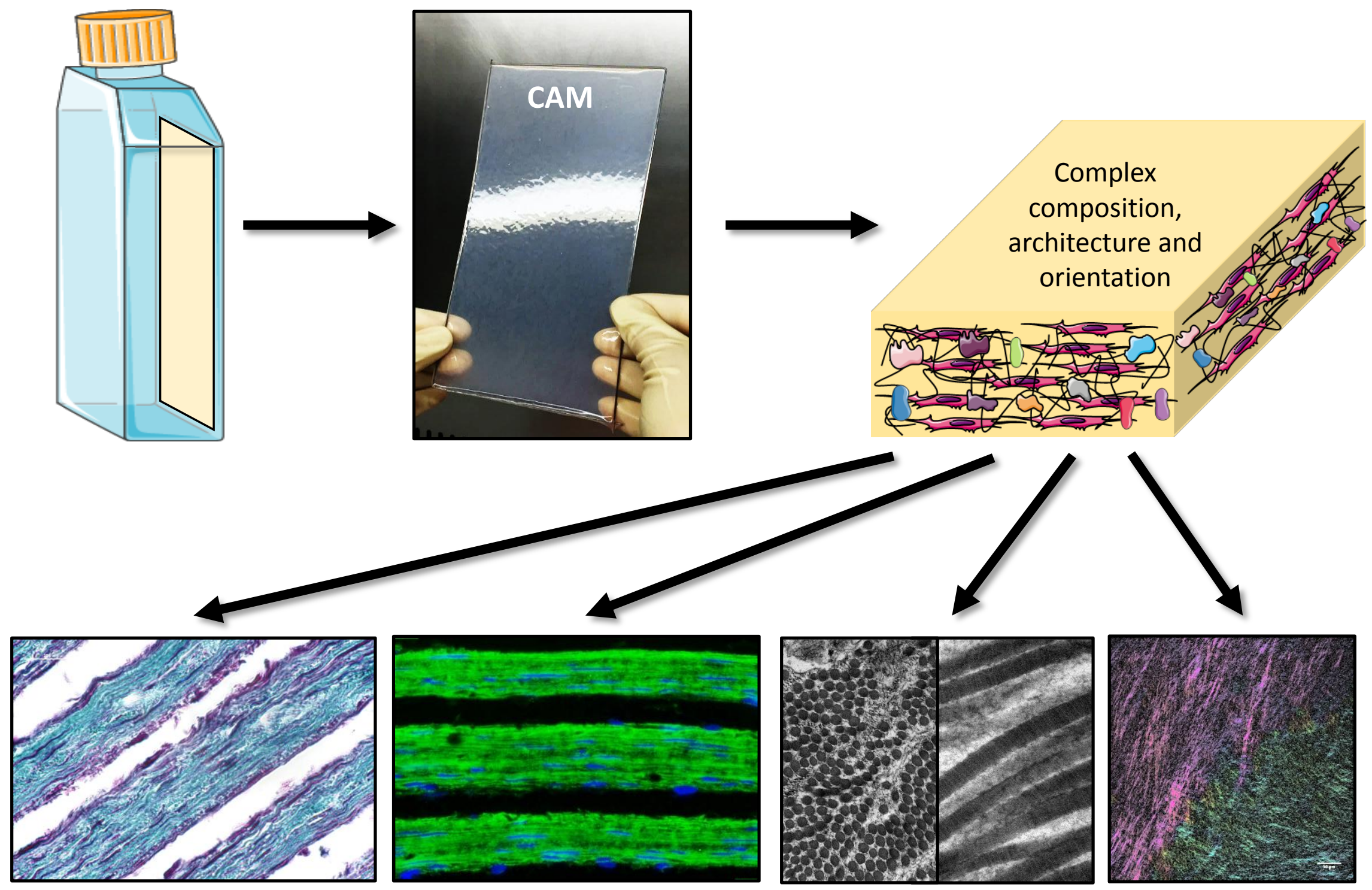
rchitecture and orientation 


\section{Title :}

Characterization of a Cell-Assembled extracellular Matrix (CAM) and effect of the devitalization process.

\section{Author names and affiliations:}

Laure Magnan $^{\mathrm{a}}$

laure.magnan@hotmail.com

Gaëlle Labrunie $^{\mathrm{a}}$

gaelle.labrunie@inserm.fr

Sylvie Rey ${ }^{\mathrm{a}}$

sylvie.rey@inserm.fr

Nathalie Dusserre ${ }^{a}$

nathalie.dusserre@inserm.fr

Nicolas L'Heureux ${ }^{a}$

nicolas.Iheureux@inserm.fr, Tel: 33 (0)5 57571488 Fax: 33 (0)5 56900517

${ }^{a}$ INSERM, Bioingénierie tissulaire, U1026, 33076 Bordeaux, France

Sébastien Marais ${ }^{\mathrm{b}}$

sebastien.marais@u-bordeaux.fr

Sabrina Lacomme ${ }^{b}$

sabrina.lacomme@u-bordeaux.fr

Etienne Gontier ${ }^{\mathrm{b}}$

etienne.gontier@u-bordeaux.fr

b UMS 3420 CNRS, US4 INSERM, Bordeaux Imaging Center, University of Bordeaux, F-33000

Bordeaux, France

Marc Bonneu ${ }^{\mathrm{c}}$

marc.bonneu@bordeaux-inp.fr 
${ }^{c}$ Plateforme Protéome, Centre de Génomique Fonctionnelle Bordeaux, Université de Bordeaux, 146 rue Léo Saignat 33076 Bordeaux Cedex France

\section{Corresponding author:}

Nicolas L'Heureux

nicolas.Iheureux@inserm.fr, Tel: 33 (0)5 57571488 Fax: 33 (0)5 56900517

${ }^{a}$ INSERM, Bioingénierie tissulaire, U1026, 33076 Bordeaux, France 


\section{Summary}

We have previously shown that the Cell-Assembled extracellular Matrix (CAM) synthesized by normal, human, skin fibroblasts in vitro can be assembled in a completely biological vascular graft that was successfully tested in the clinic. The goal of this study was to perform a detailed analysis of the composition and the organization of this truly bio-material. In addition, we investigated if the devitalization process (dehydration) used to store the CAM, and thus, make the material available "off-the-shelf," could negatively affect its organization and mechanical properties. We demonstrated that neither the thickness nor the mechanical strength of CAM sheets were significantly changed by the dehydration/freezing/rehydration cycle. The identification of over 50 extracellular matrix proteins highlighted the complex composition of the CAM. Histology showed intense collagen and glycosaminoglycan staining throughout the CAM sheet. The distribution of collagen I, collagen VI, thrombospondin-1, fibronectin-1, fibrillins-1, biglycan, decorin, lumican and versican showed various patterns that were not affected by the devitalization process. Transmission electron microscopy analysis revealed that the remarkably dense collagen network was oriented in the plane of the sheet and that neither fibril density nor diameter was changed by devitalization. Second harmonic generation microscopy revealed an intricate, multi-scale, native-like collagen fiber orientation. In conclusion, this bio-material displayed many tissue-like properties that could support normal cellECM interactions and allow implantation without triggering degradative responses from the host's innate immune system. This is consistent with its success in vivo. In addition, the CAM can be devitalized without affecting its mechanical or unique biological architecture.

\section{Statement of significance}

The extracellular matrix (ECM) defines biological function and mechanical properties of tissues and organs. A number of promising tissue engineering approaches have used processed ECM from cadaver/animal tissues or cell-assembled ECM in vitro combined with scaffolds. We have shown the clinical potential of a scaffold-free approach based on an entirely biological and human material 
produced by cells in culture without chemical processing. Here, we perform a comprehensive analysis of the properties of what can truly be called a bio-material. We also demonstrate that this material can be stored dried without losing its remarkable biological architecture.

Keywords: Tissue Engineering; scaffold-free; entirely biological; Cell-assembled extracellular matrix; mass spectrometry; collagen

\section{Introduction}

For decades, scaffolds have been seen as essential in the field of tissue engineering in order to provide the mechanical strength and geometry of the target tissue or organ. For vascular grafts, highly inert synthetic scaffolds have been used to avoid thrombosis. However, these synthetic materials are stiff, cannot be remodeled by cells, and are recognized as foreign by the body, leading to chronic inflammation, intimal hyperplasia and thrombosis. In addition, synthetic materials are notorious for keeping microorganisms out of reach from the immune system, leading to serious infections [1]. As a result, these grafts provide considerably worse outcomes than native vessels [2]. In 1989, biodegradable synthetic vascular grafts were developed to avoid chronic inflammation and its consequences [3]. A key challenge with this sort of in situ tissue-engineering is to stimulate the regeneration of a new blood vessel before the degradation of the synthetic scaffold in order to maintain sufficient mechanical strength at all times as to avoid aneurysm formation. Also, the biodegradable polymer can trigger an inflammatory response that will lead to excessive cell proliferation and stenosis, or be toxic to the cells [4]. But the idea of designing biomaterials to interact with the body, rather than try to hide from it, has continued to grow and has become a leading research strategy nowadays. From this point of view, a natural material could be seen as the ultimate biomaterial. While processed/purified proteins have been widely used, they lose their natural conformation during processing and are typically recognized as foreign and rapidly degraded upon implantation [5]. Alternatively, cadaver and animal tissues have been used but they require either chemical crosslinking (animal) to denature their foreign markers, or, more recently, an 
aggressive decellularization process (human) to remove all allogenic components [6]. Chemically cross-linked tissues are successfully used for some vascular applications (heart valves) but they do cause chronic inflammation with the consequences mentioned above and suffer from a slow degenerative process [7]. While decellularization is an option that is actively researched, there is a risk that a process aggressive enough to remove all the allogeneic components will also damage the native extracellular matrix (ECM) and, hence, make it a target of the innate immune system [8] [9].

We have long proposed that the ideal "bio-material" is, indeed, the native human ECM [10]. To avoid denaturation from physico-chemicals processing, we pioneered the use of Cell-Assembled extracellular Matrix (CAM) synthesized by normal, human, skin fibroblasts in vitro. This CAM has impressive mechanical strength and emerged as a promising "scaffold" to produce strong vascular grafts without the need for synthetic materials [11]. Autologous and living CAM-based vascular grafts were the first tissue-engineered blood vessels (TEBVs) to be implanted in the human arterial circulation and shown to have remarkable patency as arteriovenous shunts [12] [13]. More recently, allogeneic grafts that were simply devitalized by dehydration performed well in critically ill patients, demonstrating the feasibility of an "off-the-shelf" approach [14]. However, this bio-material can also be used as the conjunctive component of many other tissues such as skin, cornea, ligaments, heart valves, bones, nerves, microvascularized tissues and others [15] [16].

While this rapid and successful clinical translation has shown the potential of CAM-based tissues, only anecdotal data has been gathered on the basic molecular composition and the organization of the CAM. Indeed, previous studies were primarily focused on the mechanical properties of the CAM to support safety and quality control requirements. Understanding the structure of the CAM can help predict and/or understand its biological and mechanical properties both in vitro as well as after implantation. Therefore, the goal of this study was to perform a detailed analysis of the composition and the organization of the CAM using various approaches. In addition, we investigated if the 
dehydration/rehydration cycle, used to devitalize and make the CAM available "off-the-shelf," negatively affected its organization and mechanical properties.

2. Materials and methods

2.1. Human Skin Fibroblasts (HSFs) extraction and cells seeding

HSFs were isolated from adult normal human skin. This study was done in accordance with article L. $1243-3$ of the code of public health and under the agreement DC-2008-412 with the University Hospital Center of Bordeaux, France (update 10/10/2014). Briefly, skin was cut in $\leq 3 \mathrm{~mm}$ strips and the dermis and epidermis were separated with a solution of thermolysin (500U, Sigma \#P1512$100 \mathrm{MG}$ ) for 2 hours at $37^{\circ} \mathrm{C}$. The dermis was scraped to remove keratinocytes and cut into small pieces. The dermis was digested with a solution of collagenase $(400 \mathrm{CDU} / \mathrm{ml}$, Worthington \#44A14742A) during 3 hours at $37^{\circ} \mathrm{C}$ into a digestion chamber. The resulting solution was filtered on a $40 \mu \mathrm{m}$ cell strainer and centrifuged. Fibroblasts were seeding with a density of $1.10^{4}$ cells $/ \mathrm{cm}^{2}$ in DMEM/F-12 media (Gibco, \#31331-028) supplemented with 20\% FBS (1:1 Biowest \#S1810.500:Hyclone \#SH30109.03) and 1X Pen/Strep (Gibco \#15140-122).

\subsection{CAM culture and devitalization}

HSFs cultured for 8 weeks with DMEM/F-12 supplemented with 20\% FBS, 1X Pen/Strep and $500 \mu \mathrm{M}$ of sodium L-ascorbate (Sigma, \#A4034-500G) in T-225 produced the CAM. The media was changed 3 times per week. CAMs were also produced in 6-well plates. To devitalize the tissue, CAM were quickly rinsed in distilled water and dried at room temperature under a biosafety cabinet. Dried CAM was stored at $-80^{\circ} \mathrm{C}$. Prior to use, CAM was rehydrated in water for at least $1 \mathrm{hr}$.

\subsection{Thickness measurement}


Nine small pieces $\left(0.25 \mathrm{~cm}^{2}\right)$ of CAM were cut from 6 wells circular CAM grown in a 6 well-plate that were wither fresh or devitalized/rehydrated. Each piece were put on a metallic tube of know diameter and placed in a laser micrometer (Xactum, AEROEL) to measure the thickness.

\subsection{Perforation test}

Six well-plate CAMs were clamped with a plastic support which was placed on a tensile testing machine (AGS-X, Shimadzu). A spherical indenter, with a Teflon ${ }^{\circledR}$ ball $9 \mathrm{~mm}$ in diameter, perforated the CAM at $20 \mathrm{~mm} / \mathrm{min}$ to determine its mechanical strength $(n=6)$.

\subsection{Mass spectrometry}

\subsubsection{Sample Preparation}

Sample preparation is largely based on the method previously described by Hill RC et al. (2015) [17]. Approximately $0.5 \mathrm{~cm}^{2}$ of CAM was cut into small pieces and then rehydrated for 3 hours in $300 \mu \mathrm{L}$ of a high salt buffer (50 mM Tris-HCl, $0.25 \%$ CHAPS, 25 mM EDTA, $3 \mathrm{M} \mathrm{NaCl}, \mathrm{pH} 7.4$ ) supplemented with $30 \mu \mathrm{L}$ of protease inhibitor cocktail (Sigma-Aldrich). The hydrated CAM was spun at $10,000 \mathrm{rpm}\left(4^{\circ} \mathrm{C}\right)$ for $10 \mathrm{~min}$. The resultant supernatant was removed and the pellet was further extracted with $300 \mu \mathrm{L}$ high salt buffer two times. The pellet was then extracted at room temperature in $300 \mu \mathrm{L}$ of urea extraction buffer (6 M Urea, $2 \mathrm{M}$ Thiourea, 100 mM Ammonium Bicarbonate, $10 \mathrm{mM}$ Dithiothreitol, $\mathrm{pH}$ 8.0). The hydrated CAM was spun at $10,000 \mathrm{rpm}\left(4^{\circ} \mathrm{C}\right)$ for $10 \mathrm{~min}$. Finally, the resulting pellet was chemically digested with $50 \mu \mathrm{L}$ of $100 \mathrm{mM} \mathrm{CNBr}$ in $86 \%$ TFA overnight in the dark.

This final fraction was washed with $50 \mu \mathrm{L} d \mathrm{dH} 20$ and speed-vacced to dryness six times for one hour. The last pellet was taken up with $10 \mu \mathrm{L}$ of $100 \mathrm{mM}$ Ammonium Bicarbonate and $6 \mu \mathrm{L} 6 \mathrm{M}$ Urea, 100 $\mathrm{mM}$ Tris- $\mathrm{HCl} \mathrm{pH} 8.0$ at room temperature for $30 \mathrm{~min}$. Sample was then reduced, alkylated, and digested with trypsin as follows : (i) $1 \mu \mathrm{L} 200 \mathrm{mM}$ Dithiothreitol was added and then the sample was incubated at room temperature for $60 \mathrm{~min}$, (ii) after $2 \mu \mathrm{L} 1 \mathrm{M}$ lodoacetamid were added, the sample was incubated in the dark at room temperature for $60 \mathrm{~min}$, (iii) . $31 \mu \mathrm{L} 100 \mathrm{mM}$ Ammonium 
Bicarbonate and $10 \mu \mathrm{L}$ Trypsin $(10 \mathrm{ng} / \mu \mathrm{L})$ were finally added, the sample was incubated at $37^{\circ} \mathrm{C}$ overnight. After adding $40 \mu \mathrm{L}$ of $100 \mathrm{mM}$ Ammonium Bicarbonate, the sample is desalted using a ZipTip (Omix Tip C18 $100 \mu$ L, Agilent).

\subsubsection{Liquid Chromatography Tandem Mass Spectrometry}

The peptide mixtures were analyzed on an Ultimate 3000 nanoLC system (Dionex) coupled to a nanospray Q-Exactive quadrupole Orbitrap benchtop mass spectrometer (Thermo Fisher Scientific, San Jose, CA, USA). nLC-MS/MS analysis was done by loading ten microlitres of peptide digests onto a 300-Im inner diameter $\times 5$-mm C18 PepMapTM trap column (LC Packings) at a flow rate of $30 \mathrm{ll} / \mathrm{min}$. The peptides were eluted from the trap column onto an analytical 75-mm id $\times 15-\mathrm{cm}$ C18 Pep-Map column (LC Packings) with a 4-40\% linear gradient of solvent B in 108 min (solvent A was $0.1 \%$ formic acid in $5 \%$ ACN, and solvent $B$ was $0.1 \%$ formic acid in $80 \%$ ACN). The separation flow rate was set at $300 \mathrm{nl} / \mathrm{min}$. The mass spectrometer operated in positive ion mode at a 1.8-kV needle voltage. Data were acquired using Xcalibur 2.2 software in a data-dependent mode. MS scans ( $\mathrm{m} / \mathrm{z} 300-2,000$ ) were recorded at a resolution of $R=70,000$ (@ m/z 200) and an AGC target of $1 \times 106$ ions collected within $100 \mathrm{~ms}$. Dynamic exclusion was set to $30 \mathrm{~s}$, and top 15 ions were selected from fragmentation in HCD mode. MS/MS scans with a target value of $1 \times 105$ ions were collected with a maximum fill time of $120 \mathrm{~ms}$ and a resolution of $\mathrm{R}=35,000$. Additionally, only +2 and +3 charged ions were selected for fragmentation. Other settings were as follows: no sheath nor auxiliary gas flow, heated capillary temperature, $200^{\circ} \mathrm{C}$; normalized $\mathrm{HCD}$ collision energy of $25 \%$ and an isolation width of 3 $\mathrm{m} / \mathrm{z}$.

Data were searched by SEQUEST through Proteome Discoverer 1.4 (ThermoFisher Scientific Inc.) against the Human Reference Proteome Set (UniProt_2016_10_homo_sapiens; 70671 entries). Spectra from peptides higher than 5,000 Da or lower than 350 Da were rejected. The search parameters were as follows: Precursor tolerance was set to $10 \mathrm{ppm}$ and fragment tolerance was set at 0.02 Da for FTMS MS/MS data or $0.6 \mathrm{Da}$ for In Trap MS/MS data. Only b- and yions were 
considered for mass calculation. Oxidation of methionine (+16 Da) was considered as variable modifications, and carbamidomethylation of cysteines (+57 Da) was considered as fixed modification. Two missed trypsin cleavages were allowed. Peptide validation was performed using Percolator algorithm (Kall et al, 2007), and only "high confidence" peptides were retained corresponding to a $1 \%$ falsepositive rate at peptide level.

\subsection{Histology and immunofluorescence}

Hydrated CAMs were fixed in 4\% PFA overnight. After 2 rinses in PBS, CAMs were rolled, dehydrated and embedded in paraffin. Paraffin sections $(7 \mu \mathrm{m})$ were deparaffinized in toluene for $3 \times 5$ minutes, followed by a descending series of ethanol and those were colored with Masson's trichrome and alcian blue or processed for immunofluorescence.

The following antibodies used for staining were purchased from Abcam: rabbit polyclonal antibodies against collagen-I (ab34710), collagen-VI (ab6588), versican (ab19345), fibrillin-1 (ab53076), fibronectin (ab23750), thrombospondin (ab85762), lumican (ab98067) and mouse monoclonal antibodies against decorin (ab54728) and biglycan (ab54855).

Deparaffinized sections were pretreated with citrate $\left(\mathrm{pH}\right.$ 6.0) for 20 minutes at $95^{\circ} \mathrm{C}$ and then were washed with PBS. To block non-specific binding sites, 5\% goat normal serum in PBS was used for 30 minutes at room temperature. Antibodies diluted in 5\% goat serum in PBS (1:50 - 1:200) were applied on sections overnight at $4^{\circ} \mathrm{C}$. Negative controls had no primary antibodies. Secondary antibodies Alexa Fluor 568-conjugated goat anti-rabbit (Invitrogen, A-11036) and anti-mouse (Invitrogen, A-1104) were diluted (1:300) in presence of DAPI (1:1000) and applied during $2 \mathrm{~h}$ at ambient temperature. Cross sections of human artery were used as positive control.

Images were acquired using an epifluorescence microscope (Nikon, Eclipse 80i).

\subsection{Transmission electron microscopy}


CAMs were fixed with $2 \%(\mathrm{v} / \mathrm{v})$ paraformaldehyde $2 \%(\mathrm{v} / \mathrm{v})$ glutaraldehyde in $0.1 \mathrm{M}$ sodium cacodylate buffer $(\mathrm{pH} 7.4)$ at $4^{\circ} \mathrm{C}$ overnight. Then a new fixation was made in $1 \%(\mathrm{v} / \mathrm{v})$ paraformaldehyde in $0.1 \mathrm{M}$ sodium cacodylate buffer $\left(\mathrm{pH} \mathrm{7.4)}\right.$ at $4^{\circ} \mathrm{C}$ overnight. Samples were washed in $0.1 \mathrm{M}$ sodium cacodylate buffer $(\mathrm{pH} 7.4)$ and then post-fixed in a mix $1 \%$ osmium tetroxide $(\mathrm{v} / \mathrm{v}) /$ $1 \%$ potassium ferricyanide $\mathrm{K}_{3} \mathrm{Fe}(\mathrm{CN})_{6}(\mathrm{wt} / \mathrm{v})$ in $0.1 \mathrm{M}$ sodium cacodylate buffer during $1 \mathrm{~h} 30$ at room temperature in the dark to enhance contrast. After extensive washing in $0.1 \mathrm{M}$ sodium cacodylate buffer, samples were transferred to $1 \%(\mathrm{wt} / \mathrm{v})$ tannic acid in $0.1 \mathrm{M}$ sodium cacodylate buffer for $1 \mathrm{~h} 30$ at RT then washed in water many times. In order to enhance contrast more, samples were then stained en bloc in $1 \%(\mathrm{wt} / \mathrm{v})$ aqueous uranyl acetate solution at $4^{\circ} \mathrm{C}$ overnight, in the dark. Subsequently, after washing in water, CAMs were dehydrated through a series of graded ethanol followed by propylene oxide, then infiltrated in series of mixtures of propylene oxide and epoxy resin (Epon 812; Delta Microscopies, Toulouse, France) - Graduated mixtures - followed by embedding in $100 \%$ resin overnight at RT. Next day, a new embedding in pure resin was made all day at RT before polymerization over a period between $24-48$ hours at $60^{\circ} \mathrm{C}$. Samples were then sectioned perpendicularly and longitudinally using a diamond knife (Diatome, Biel-Bienne, Switzerland) on an ultramicrotome (EM UCT, Leica Microsystems, Vienna, Austria). Ultrathin sections (65 nm) were picked up on copper grids and then stained with uranyl acetate and lead citrate. Grids were examined with a transmission electron microscope (H7650, Hitachi, Tokyo, Japan) at 80kV. Images were then analyzed with Image J.

\subsection{Second harmonic generation}

The microscope used for mosaics of images in Second Harmonic Generation (SHG) was a Leica TCS SP5 on an upright stand DM6000 (Leica Microsystems, Mannheim, Germany) equipped with a resonant scanner $(16000 \mathrm{~Hz}$ in bidirectional mode). The excitation was done with a tunable femtosecond pulsed laser Mai Tai HP (Spectra-Physics, Irvine, USA) tuned at $896 \mathrm{~nm}$. The detection was done on a PMT multi-alkali placed in the transmission pathway, equipped with a bandpass 
emission filter 458/20 nm and a $680 \mathrm{~nm}$ blocking edge short-pass filter (Semrock, Rochester, USA). An 8-times averaging is done on each image to improve the signal to noise ratio. The continuous mosaic of $9 \mathrm{~mm} \times 4.5 \mathrm{~mm}$ was done at several depths using an objective HCX Plan Apo CS 20X multiimmersion NA 0.70, a XY motorized stage (Märzhäuser, Wetzlar, Germany) and a Super-Z scanning stage for Z positioning (Leica Microsystems, Mannheim, Germany). Each field of view represents a size of $500 \mu \mathrm{m}$ in $\mathrm{X}$ and $\mathrm{Y}$ (pixel size around $500 \mathrm{~nm}$ ). The mosaic was automatically reconstructed by the software LAS AF (Leica Microsystems, Mannheim, Germany). The discontinuous mosaic of $15 \mathrm{~mm}$ x $35 \mathrm{~mm}$ was done at the depth of $30 \mu \mathrm{m}$ in the same conditions than previously described. The different fields of view were done each $1 \mathrm{~mm}$ in $\mathrm{X}$ and $\mathrm{Y}$. The analysis of these mosaics was done on the ImageJ plugin OrientationJ (Daniel Sage, EPFL, Switzerland), by using the Distribution module [18].

\subsection{Statistical analyses}

All statistical analyses were performed with GraphPad Prism, Version 6 (GraphPad Software Inc. USA). Data is presented as mean \pm standard deviation (SD). Differences between the groups were determined on basis of analysis of variance (ANOVA) with Tukey's multiple comparison tests. Differences were considered significant at $p<0.05$.

\section{Results}

\subsection{Devitalization of the Cell-Assembled Matrix (CAM)}

Human Skin Fibroblasts (HSFs) were isolated from adult normal human skin and cultured during 8 weeks in order to obtain a strong and cohesive living sheet. Figure $1 \mathrm{~A}$ shows a $18 \times 10 \mathrm{~cm}$ homogeneous and semi-transparent sheet freshly detached from a T-225 flask. Although fresh sheets can be used if living fibroblasts are deemed important for a particular assembly strategy or application [13] [19], devitalization by dehydration is a convenient and relatively non-traumatic method to store the Cell-Assembled Matrix (CAM). However, it is important to determine if this 
process significantly affects the CAM quality and structure. From a basic handling point of view, the devitalization did not affect the thickness nor the strength of the CAM after rehydration (Figures $1 \mathrm{~B}$ \& C), which supports the idea that dehydration is a "gentle" and essentially reversible process for the ECM. Figure 1D shows the linear increase of the strength up to 14 weeks, highlighting the remarkable mechanical strength $(<1500$ gf at 14.7 weeks) that these tissues can develop. The continuous synthesis of extracellular matrix is a convenient way to control and, to a certain point, to predict the strength of the tissue.

\subsection{Composition of the CAM}

A thorough proteomic analysis of the CAM reveled a complex composition with 56 positively identified matrix proteins (Table 1). We initially used a classic urea/thiourea extraction. While this treatment solubilized 46 matrix proteins, it did not macroscopically appear to dissolve the CAM. To insure that we were detecting all the proteins of the CAM, an additional and more aggressive extraction with cyanogen bromide was performed to effectively dissolve the CAM. Surprisingly, only 10 additional proteins were identified (marked with * in Table 1). Proteins were classified in 15 families including members of 4 of the 5 collagen families: fibril-forming collagens (collagens I, III and V), FACITs (collagens XII and XIV), beaded filaments collagens (collagens VI) and multiplexin collagens (collagens XV and XVIII). In addition, a variety of proteoglycans were present in the CAM. Fourteen proteins implicated in cell-matrix and matrix-basement membrane interactions (thrombospondin-1, galectin-1, prolargin, periostin, etc.) were also identified. Importantly, 8 proteins of the CAM were linked to elastic fibers (fibulins, fibrillin-1, elastin, etc.). Elastin is a notoriously difficult protein to extract and process. Taken together these results highlight that the CAM is a dense and naturally highly cross-linked matrix showing a complexity similar to that of native ECM suggesting that it could support a variety of biological activities.

\subsection{Organization of the CAM}


Next, we looked at the microscopic organization of the CAM. Basic histology confirmed some of the proteomic data. It revealed an abundant and dense fibrillar collagens network throughout the thickness of the sheet as well as a large presence of glycosaminoglycans (Figure 2). Fibroblasts were concentrated on the surface of the sheet while cells embedded in the matrix were very flat and elongated in the $X Y$ plane of the sheet. Superficial cell layers were largely lost during the dehydration/rehydration cycle but the collagen network and glycosaminoglycans appeared unaffected. Although cells were dead, their nuclear material was clearly stained.

\subsection{Extracellular matrix proteins distribution}

We used immunofluorescence to study the distributions of some key proteins identified by mass spectrometry and how they may have been affected by the devitalization process (Figure 3). As expected the mechanical backbone of collagen I was homogeneously distributed through the thickness of the CAMs. A similar intense and even distribution was observed for collagen VI which is typically associated with the fibrillar collagen network but plays a key role in the complex cellular architecture of tissues [20]. Thrombospondin-1, another protein with an important role in cell-matrix interactions [21], had a similarly ubiquitous distribution. Fibronectin, however, had a heterogeneous distribution and was clearly concentrated on the outer surfaces of the sheet. Since fibronectin is a well-known integrin ligand, this distribution could significantly facilitate cell seeding of the CAM. The devitalization process did not affect the localization of these proteins. Fibrillin-1 is the main component of microfibrils that provides force-bearing structural support in elastic connective tissue [22]. It was distributed near the cells of the sheets and, since the devitalization removed the superficial cellular components, it was less abundant on the surfaces of the sheet after processing.

\subsection{Proteoglycans distribution}

Four important proteoglycans were stained by immunofluorescence: biglycan, decorin and lumican, which are Small Leucine-Rich Proteoglycans (SLRPs), and versican, a chondroitin sulfate proteoglycan (Figure 4). Biglycan and decorin were homogeneously distributed through the thickness of the fresh 
CAM. The staining of devitalized CAM showed a lower signal and, for biglycan, the pericellular staining became more obvious. Devitalization had a similar effect on lumican distribution but the pericellular staining was more punctuated. Versican was mainly localized near the cells and as cell layers were lost in the devitalized CAM, less staining was observed. To conclude, devitalization had a negligible effect on the structure and the distribution of proteins.

\subsection{Fibrillar collagen network}

As suggested by Table 1 and Figure 3, fibrillar collagen was the main component of the CAM. The strength of the CAM will depend on the distribution and the density of the collagen fibrils. In addition, we believe that the intact "native" ultrastructural architecture of the CAM will be crucial for a successful in vivo integration. Transmission electron microscopy was performed to study the ultrastructural organization with cross sections and sections parallel to the XY plane of the sheet (Figure 5). Almost all fibrils appeared to be in the XY plane. Fibrils were grouped in high-density bundles and were oriented in various directions within the $X Y$ plane. At higher magnification, the typical striated organization of the collagen fibrils was visible as well as a network of microfibrils surrounding the collagen network reminiscent of native ECM. As previously shown (Figures $2 \& 3$ ), cells were embedded in a dense fibrillar network. Despite the devitalization process, cell bodies are easily identifiable and no gaps in the CAM were visible.

\subsection{Fibril density and diameter}

Next, we quantified fibril density through the thickness of the sheet and the impact of the devitalization process. Figure $6 \mathrm{~A}$ showed that the fibrillar density through the thickness varied between very dense regions of fibrils (density $y_{\max }\left(\right.$ fresh) $=134$ fibrils $/ \mu \mathrm{m}^{2}$ ) and some very thin ones (density $y_{\min }\left(\right.$ fresh) $=9$ fibrils $/ \mu \mathrm{m}^{2}$ ) where the cells were located. The overall fibril density of fresh CAM was $53 \pm 7$ fibrils $/ \mu m^{2}$ which was not significantly different from the devitalized/rehydrated one (47 \pm 6 fibrils $\left./ \mu \mathrm{m}^{2}\right)$. Similarly, no significant difference was observed between the diameter of fibrils in fresh and devitalized/rehydrated sheets with an average value of $45 \pm 3 \mathrm{~nm}$ (Figure 6B). 


\subsection{Collagen fibers orientation}

The mechanical properties of a tissue is not only given by the structure and the density of collagen fibrils but also by the orientation and the organization of the fibers. In order to have a more global view of the collagen network organization, we performed a second harmonic generation (SHG) analysis of the collagen fiber orientation in the XY plane of a CAM sheet at various scales and depth (Figures 7, $8 \& 9$ ). In a continuous mosaic of $4.5 \times 9 \mathrm{~mm}$ at a depth of $28 \mu \mathrm{m}$, collagen fibers were grouped in bundles oriented in different directions (Figure 7A). The higher magnification of two locations in the CAM (Figure 7B) showed that in a field of $0.25 \mathrm{~mm}^{2}$, the orientation could change from a largely isotropic distribution to a much more anisotropic one. To explore an even larger CAM area, SHG was performed on a sample of $15 \times 35 \mathrm{~mm}$ by taking images of $500 \times 500 \mu \mathrm{m}$ every $1 \mathrm{~mm}$ to create a discontinuous mosaic (Figure $8 \mathrm{~A}$ ). Since collagen fibers would no longer be clearly visible in that mosaic, we assigned a vector to each field to show the average fiber orientation. We then determined what sample area was needed to achieve a constant orientation distribution (Figure 8B). This analysis revealed that an area of at least $324 \mathrm{~mm}^{2}$ was needed to properly asses the fiber orientation. Furthermore, this study showed that fiber orientation was not isotropic and favored an angle of -20 degrees in the XY plane, corresponding approximately to the direction of the width of the sheet.

\subsection{Complex fiber orientation}

Next, we looked at how collagen fibers orientation was changing through the thickness of the CAM (Figure 9). Results showed that the orientation could be very different according to the depth. At the same location, at a depth of $12 \mu \mathrm{m}$, the behavior was anisotropic with a preferential angle of 40 degrees, whereas at a depth of $36 \mu \mathrm{m}$, fiber orientation was more isotropic. This variability suggested that the sequential synthesis of the matrix during the cell culture resulted in several layers of collagen fibers with different orientations. This extremely complex and variable collagen fiber 
orientation is reminiscent of what is observed in many conjunctive tissues in vivo and can explain the surprising mechanical resilience of this bio-material.

\section{Discussion}

In this study, we provided a detailed characterization of what can truly be described as a biomaterial. The ECM synthesized by normal, human skin fibroblasts in vitro has both substantial mechanical properties as well as native-like biological composition. We demonstrated the very complex composition of the ECM (over 50 proteins) identifying members of a wide range of protein families. This complexity is typical of the ECM of natural organs [23] [24] [25]. This complexity is critical for the formation of complex molecular networks with a multiscale organization. Such complexity is also essential for biological functions of an ECM, which include presentation of an array of integrin ligands, playing the role of a growth factor reservoir and, by influencing expression and storage of matrix metalloproteinases (MMPs) [26] and their tissue inhibitors (TIMPS) [27]. These are functions necessary to allow physiological processes such as angiogenesis, the formation of specific cellular niches for cell differentiation, or additive, or subtractive, remodeling. Finally, a complex ECM is also necessary to support the fibrillar collagen type I network to insure its initial mechanical strength as well as its stability by both ensuring proper fibrillogenesis and resistance to MMPs [28]. For example, the roles of tenascin and collagen $\mathrm{V}$ have been identified in the Ehlers-Danlos Syndrome which is characterized by hypermobility of the joints and high levels of skin laxity du to ECM abnormalities [29] [30]. In addition, collagen VI has been shown to accelerate collagen fibril formation in vitro [20]. These are only a few examples of the important biological functions that can play lesser-known ECM proteins in the well-known mechanical role of the collagen I fibrillar network.

However, the properties of the ECM is not only dependent on its molecular composition but relies heavily on the organization of its components. We observed different patterns of non-collagenous protein distribution that suggest differences in deposition dynamics. These patterns may be 
important to understand the behavior of this material both in vitro, in the case of cell seeding experiments for example, and in vivo, when analyzing remodeling responses. For example, the fact that fibronectin appears to be concentrated on the surface of the CAM sheet could indicate that it is only deposited by active and/or migrating cell. It also may be that fibronectin deposited within the sheet was progressively removed as cells in the center of the sheet became more quiescent. These are only hypothesis that would need to be confirmed with further experiments.

The deposition pattern of the collagen, seen both in immunofluorescence and histology, showed a lamellar disposition uniformly distributed throughout the thickness of the tissue, which suggests that the deposition process was continuous throughout the 8-week production process. This process appears to continue at the same rate at longer time points since the strength of the sheet continued to increase linearly up to 14 weeks (Figure 1D). Ultrastructural analysis of the collagen network organization revealed that collagen fibrils were densely packed into arrays adopting various directions (Figure 5E) but almost exclusively aligned with the plane of the sheet, which is coherent with the observed lamellar structure. Also coherent with a continuous synthesis process, was the observation that fiber density distribution (and diameter) was constant throughout the thickness of the sheet. Ultrastructural analysis also revealed a complex network of microfibrils around the collagen fibrils which is consistent with the complex molecular composition observed and highlights the difference between the CAM and reconstituted collagen-based constructs where such structures are not observed [31]. The individual collagen fibrils had the typical striation pattern (or d-banding) but its periodicity $(56.8 \pm 3.9 \mathrm{~nm}$ ) was somewhat shorter than the canonical value of $67 \mathrm{~nm}$ of collagen Type I native fibrils [32]. However, collagen periodicity has been known to vary significantly due to histological preparations, to the stress state of the matrix, hydration degree, etc. and, in fact, a wide range of values have been observed [33] [34] [35]. In addition, collagen fibrils periodicity, length and width can all be controlled by the presence of so-called "minor" collagens and other ECM proteins that have been shown to be abundant in the CAM [32]. Niklason has reported a periodicity 
value of $59.2 \pm 0.7 \mathrm{~nm}$, which is similar to ours, for the collagen in her tissue engineered blood vessel and she showed it to be the same as for the collagen of the media of the carotid artery [36].

The typical swirling patterns observed in confluent fibroblast cultures producing sheets are fairly large (approximately $500 \mu \mathrm{m}$ ) and suggest that there might be a ECM deposition pattern of similar scale (results not shown). We wanted to determine the scale of this pattern because it may dictate how thin a tissue can be cut from these sheets without risking to observe weaknesses created by this pattern. For example, in a mesh with a mesh size of $1 \mathrm{~mm}$, one would not want to cut $3 \mathrm{~mm}$ strips because you might have either 1 or 2 closed mesh (50\%) in any give sample. We used SGH microscopy to perform a detailed study of the orientation of the collagen fibers on larger areas. Our analysis showed a large variability of fiber orientation in smaller areas but revealed that on areas above $324 \mathrm{~mm}^{2}$, the average collagen fiber orientation was constant, which gives us some indication of the tissue macrostructure. Further analysis in the depth of the tissue revealed a similar variability of fiber orientation which reveals an extremely complex tridimensional structure that explains the remarkable resilience of this tissue and is very similar to what is observed in vivo [37].

In our previous studies, we have implanted CAM-based blood vessels in clinical with great success [12] [38] [14] [39]. These vessels contained some or were made entirely of devitalized CAM. We have chosen to use a devitalization process instead of a decellularization process to avoid damaging the ECM through chemical extractions. We do not believe it to be necessary since our tissue contains only allogeneic fibroblasts which are poorly immunogenic and are well tolerated in commercially used tissue engineered products [40] [41] [42]. In addition, our devitalization process, by destroying cell structures, could further reduce immunogenicity of the material [43]. This view is supported by our most recent clinical cases where we looked specifically for cellular and antibody driven immunological response to an allogenic graft and saw none [14].

An important goal of this study was to demonstrate that the devitalization process does not adversely affect the quality of the CAM since this is the central advantage of this approach. The 
devitalization process is a convenient way to stabilize and store the CAM before manufacturing and CAM products after manufacturing. Unlike decellularization, it is rapid, does not require special equipment or reagents, will not leave chemical residues and most importantly, as we demonstrated here, is a very gentle process for the ECM. Indeed, the process has no macroscopic effect on the sheet and we have shown that it does not change its strength or thickness. Histologically, except for the loss of superficial cell-associated material, the structure of the sheets also appears undisturbed. While many proponents of decellularization would stop there to show "no effect" of their process, we went further and shown that the presence and distributions of many key proteins were not significantly affected by the process. We even looked at the ultrastructural level and showed that the collagen fibril distribution as well as diameter were not changed. When we know that decellularization can remove of to $95 \%$ of some proteins [8], we believe that this process is, indeed, a very gentle one that can keep most, if not all, the biological and mechanical properties of this materiel.

\section{Conclusion}

In conclusion, we have shown that the CAM is a remarkably complex extracellular matrix both by its composition as well as by its organization. This complexity is the hallmark of natural ECMs of which we are still discovering secrets to this day. This combination of native-like structure and composition makes this true bio-material a unique candidate providing both mechanical and biological cues that are required to replace and to be remodeled into many types of tissues. The CAM comes in a convenient sheet form that can be rolled, cut, folded, perforated, laminated, etc. and we have shown that is can also be stored dried at $-80^{\circ} \mathrm{C}$ until needed without losing its unique properties.

\section{Acknowledgments}

This work was supported by Ministère de la Recherche et de l'Enseignement Supérieur in 2015, Chaire seniore de l'Initiative d'Excellence de l'Université de Bordeaux (IdEx Bordeaux) in 2015 and Agence Nationale de la Recherche (ANR-16-CE18-0024-01) in 2016 of France.

We thank Dr Reine Bareille and Pr Philippe Pélissier to help in the procurement of skin samples. 
Legends

Figure 1: Devitalization of the living sheets did not affect the thickness and the strength of the Cellassembled extracellular matrix (CAM). (A) Macroscopic image of a fresh sheet detached from the flask after 8 weeks of culture. A devitalized CAM had a similar appearance. (B) Thickness comparison between fresh and devitalized/rehydrated CAMs $(p>0.05, n=6)$. (C) Strength comparison between fresh and devitalized/rehydrated CAMs $(p>0.05, n=6)$. (D) Perforation strength of sheets cultured up to 14 weeks (linear regression, $R^{2}=0.99, n=6$, one representative experiment of three).

Table 1: The Cell-assembled extracellular matrix (CAM) was a very rich tissue with 56 proteins identified by mass spectrometry. Proteins were extracted using urea/thiourea or cyanogen bromide and identified by LC-MS/MS. Asterix indicate proteins that were only identified after cyanogen bromide extraction. The number indicates the order of appearance during the identification.

Figure 2: Devitalization did not affect the very dense network of fibrillar collagen or the proteoglycan content. Fresh and devitalized/rehydrated CAMs were fixed, rolled on themselves, cross sectioned and stained with (A) Masson's Trichrome to show collagen (blue-green) and (B) Alcian Blue to show glycosaminoglycans (blue). The brace shows one sheet layer. The living fibroblasts (A), in purple, were embedded in a very dense collagen network and are still stained after devitalization (B). Scale bar $=20 \mu \mathrm{m}$.

Figure 3: Devitalization did not affect the distribution of $5 \mathrm{ECM}$. Sheets of fresh and devitalized/rehydrated CAMs were rolled and cross sectioned. Collagens I and $\mathrm{VI}$ and Thrombospondin-1 were homogeneously distributed through the thickness of the CAM. Fibronectin was localized throughout the thickness of the sheet but more concentrated on the surface. Fibrillin-1 was detected near the fibroblasts and, as superficial cell layers were lost in the devitalized CAM, less staining was observed. Nuclei are in bleu. Scale bar $=20 \mu \mathrm{m}$.

Figure 4: Devitalization did not affect the distribution of 4 proteoglycans. Sheets of fresh and devitalized/rehydrated CAMs were rolled, cross sectioned and immunostained. Biglycan and decorin were homogeneously distributed through the thickness of the Fresh CAM. The staining of devitalized CAM showed a lower signal and for biglycan a higher cell staining. Lumican was distributed on the whole surface of the CAMs with a more specific cell staining in the Fresh CAM. Versican was mainly localized near the cells and, as cell layers were lost in the devitalized CAM, less overall staining was observed. Scale bar $=20 \mu \mathrm{m}$.

Figure 5: Collagen fibrils were organized in bundles almost exclusively in the XY plane. CAM were cut parallel to the surface of the sheet ( $\mathrm{XY}$ red plane) or perpendicularly ( $\mathrm{YZ}$ green plane) and collagen fibrils were observed by transmission electron microscopy. (A-C) YZ sections (green frames) reveled mainly cross sectioned fibrils (appear circular). (D-F) XY sections (red frames) showed almost exclusively longitudinal section of the collagen fibrils with the typical striated structure. The fibrils were grouped by very dense bundles oriented in various directions but within the XY plane. A complex network of microfibrils is visible at higher magnifications.

Figure 6: Devitalization did not affect collagen fibril density and diameter. (A) Fibrils of fresh and devitalized/rehydrated CAM were counted through the thickness of the sheets $(n=3)$. Histograms show the results for one representative sample. In the two conditions, the fibril density ( $d=$ density) varied between dense and sparse regions of fibrils (corresponding to cells), with no significant difference in the overall density $(p=0.3557)$. (B) Fibril diameter $(D=$ diameter) was measured 
through the thickness of fresh and devitalized/rehydrated CAM $(n=3)$. Histograms show the results for one representative sample. No significant difference was observed $(p=0.7718)$.

Figure 7: Collagen fibers adopted various orientations in a $\mathbf{4 0 . 5} \mathrm{mm}^{\mathbf{2}}$ sample. (A) A continuous mosaic of a $4.5 \times 9 \mathrm{~mm}$ CAM sample (each field $=500 \times 500 \mu \mathrm{m}$ ), at a depth of $28 \mu \mathrm{m}$, using second harmonic generation (SHG). Fibers orientation is viewed in pseudo colours. Collagen fibers were organized by bundles with various directions. (B) Higher magnification of a field of $0.25 \mathrm{~mm}^{2}$ in two locations in the CAM. The first location had an more isotropic behaviour whereas the second displayed an anisotropic one. Scale bar $=100 \mu \mathrm{m}$.

Figure 8: The CAM had a stable anisotropy over $324 \mathrm{~mm}^{2}$. (A) A discontinuous mosaic of $15 \times 35 \mathrm{~mm}$ at a depth of $30 \mu \mathrm{m}$ was created using $500 \times 500 \mu \mathrm{m}$ images taken every mm using SHG. Vectors represent the main orientation for each images. (B) Orientation distribution were measured in areas of increasing size. A stable anisotropy around -20 degrees was observed in areas of $324 \mathrm{~mm}^{2}$ or larger.

Figure 9: The collagen fibers orientation was dependent of the depth of the CAM. Collagen fibers orientation was analyzed by SHG in a sample of $0.25 \mathrm{~mm}^{2}$ at 3 different depths. This orientation varied from largely anisotropic to isotropic behaviour according to the depth. Scale bar $=100 \mu \mathrm{m}$.

Supplemental figure: Distribution of collagens and proteoglycans in human humeral artery. Human humeral artery was cross sectioned and immunostained. Collagens I, VI and fibronectin were homogeneously distributed through the thickness of the artery wall. Biglycan, decorin, lumican, versican, fibrillin-1 and thrombospondin-1 showed a pericullar staining. Thrombospondin-1 was localized in the intimal layer of the artery. $\mathrm{L}=$ lumen. Scale bar $=50 \mu \mathrm{m}$.

Bibliography:

[1] D. Shemesh, I. Goldin, J. Hijazi, I. Zaghal, D. Berelowitz, A. Verstandig, O. Olsha, A prospective randomized study of heparin-bonded graft (Propaten) versus standard graft in prosthetic arteriovenous access, Journal of Vascular Surgery. 62 (2015) 115-122. doi:10.1016/j.jvs.2015.01.056.

[2] J.M. Anderson, A. Rodriguez, D.T. Chang, FOREIGN BODY REACTION TO BIOMATERIALS, Semin Immunol. 20 (2008) 86-100. doi:10.1016/j.smim.2007.11.004.

[3] B. van der Lei, C.R.H. Wildevuur, From a Synthetic, Microporous, Compliant, Biodegradable Small-Caliber Vascular Graft to a New Artery, Thorac Cardiovasc Surg. 37 (1989) 337-347. doi:10.1055/s-2007-1020349.

[4] S. Row, H. Peng, E.M. Schlaich, C. Koenigsknecht, S.T. Andreadis, D.D. Swartz, Arterial grafts exhibiting unprecedented cellular infiltration and remodeling in vivo: The role of cells in the vascular wall, Biomaterials. 50 (2015) 115-126. doi:10.1016/j.biomaterials.2015.01.045.

[5] T. Aper, M. Wilhelmi, C. Gebhardt, K. Hoeffler, N. Benecke, A. Hilfiker, A. Haverich, Novel method for the generation of tissue-engineered vascular grafts based on a highly compacted fibrin matrix, Acta Biomaterialia. 29 (2016) 21-32. doi:10.1016/j.actbio.2015.10.012.

[6] J.H. Lawson, M.H. Glickman, M. Ilzecki, T. Jakimowicz, A. Jaroszynski, E.K. Peden, A.J. Pilgrim, H.L. Prichard, M. Guziewicz, S. Przywara, J. Szmidt, J. Turek, W. Witkiewicz, N. Zapotoczny, T. Zubilewicz, L.E. Niklason, Bioengineered human acellular vessels for dialysis access in patients with end-stage renal disease: two phase 2 single-arm trials, Lancet. 387 (2016) 2026-2034. doi:10.1016/S0140-6736(16)00557-2. 
[7] D.R. Johnston, E.G. Soltesz, N. Vakil, J. Rajeswaran, E.E. Roselli, J.F. Sabik, N.G. Smedira, L.G. Svensson, B.W. Lytle, E.H. Blackstone, Long-Term Durability of Bioprosthetic Aortic Valves: Implications From 12,569 Implants, The Annals of Thoracic Surgery. 99 (2015) 1239-1247. doi:10.1016/j.athoracsur.2014.10.070.

[8] E.A. Calle, R.C. Hill, K.L. Leiby, A.V. Le, A.L. Gard, J.A. Madri, K.C. Hansen, L.E. Niklason, Targeted proteomics effectively quantifies differences between native lung and detergent-decellularized lung extracellular matrices, Acta Biomaterialia. 46 (2016) 91-100. doi:10.1016/j.actbio.2016.09.043.

[9] T.J. Keane, R. Londono, N.J. Turner, S.F. Badylak, Consequences of ineffective decellularization of biologic scaffolds on the host response, Biomaterials. 33 (2012) 1771-1781. doi:10.1016/j.biomaterials.2011.10.054.

[10] N. L'heureux, S. Pâquet, R. Labbé, L. Germain, F.A. Auger, A completely biological tissueengineered human blood vessel, The FASEB Journal. 12 (1998) 47-56.

[11] G. Konig, T.N. McAllister, N. Dusserre, S.A. Garrido, C. Iyican, A. Marini, A. Fiorillo, H. Avila, W. Wystrychowski, K. Zagalski, M. Maruszewski, A.L. Jones, L. Cierpka, L.M. de la Fuente, N. L'Heureux, Mechanical properties of completely autologous human tissue engineered blood vessels compared to human saphenous vein and mammary artery, Biomaterials. 30 (2009) 1542-1550. doi:10.1016/j.biomaterials.2008.11.011.

[12] N. L'Heureux, T.N. McAllister, L.M. de la Fuente, Tissue-Engineered Blood Vessel for Adult Arterial Revascularization, New England Journal of Medicine. 357 (2007) 1451-1453. doi:10.1056/NEJMc071536.

[13] T.N. McAllister, M. Maruszewski, S.A. Garrido, W. Wystrychowski, N. Dusserre, A. Marini, K. Zagalski, A. Fiorillo, H. Avila, X. Manglano, Effectiveness of haemodialysis access with an autologous tissue-engineered vascular graft: a multicentre cohort study, The Lancet. 373 (2009) 1440-1446.

[14] W. Wystrychowski, T.N. McAllister, K. Zagalski, N. Dusserre, L. Cierpka, N. L'Heureux, First human use of an allogeneic tissue-engineered vascular graft for hemodialysis access, Journal of Vascular Surgery. 60 (2014) 1353-1357. doi:10.1016/j.jvs.2013.08.018.

[15] A. Lavoie, C. Fugère, A. Beauparlant, B. Goyer, D. Larouche, C. Paquet, M. Desgagné, S. Sauvé, H. Robitaille, M. Dunnwald, D.H. Kim, R. Pouliot, J. Fradette, L. Germain, Human Epithelial Stem Cells Persist Within Tissue-Engineered Skin Produced by the Self-Assembly Approach, Tissue Engineering Part A. 19 (2012) 1023-1038. doi:10.1089/ten.tea.2012.0117.

[16] C. Couture, K. Zaniolo, P. Carrier, J. Lake, J. Patenaude, L. Germain, S.L. Guérin, The tissueengineered human cornea as a model to study expression of matrix metalloproteinases during corneal wound healing, Biomaterials. 78 (2016) 86-101. doi:10.1016/j.biomaterials.2015.11.006.

[17] R.C. Hill, E.A. Calle, M. Dzieciatkowska, L.E. Niklason, K.C. Hansen, Quantification of Extracellular Matrix Proteins from a Rat Lung Scaffold to Provide a Molecular Readout for Tissue Engineering, Mol Cell Proteomics. 14 (2015) 961-973. doi:10.1074/mcp.M114.045260.

[18] Z. Püspöki, M. Storath, D. Sage, M. Unser, Transforms and Operators for Directional Bioimage Analysis: A Survey, in: Focus on Bio-Image Informatics, Springer, Cham, 2016: pp. 69-93. doi:10.1007/978-3-319-28549-8_3.

[19] N. L'Heureux, N. Dusserre, G. Konig, B. Victor, P. Keire, T.N. Wight, N.A.F. Chronos, A.E. Kyles, C.R. Gregory, G. Hoyt, R.C. Robbins, T.N. McAllister, Human tissue-engineered blood vessels for adult arterial revascularization, Nature Medicine. 12 (2006) 361-365. doi:10.1038/nm1364.

[20] M. Cescon, F. Gattazzo, P. Chen, P. Bonaldo, Collagen VI at a glance, Journal of Cell Science. 128 (2015) 3525-3531. doi:10.1242/jcs.169748.

[21] A. Resovi, D. Pinessi, G. Chiorino, G. Taraboletti, Current understanding of the thrombospondin1 interactome, Matrix Biology. 37 (2014) 83-91. doi:10.1016/j.matbio.2014.01.012.

[22] T. Krieg, M. Aumailley, The extracellular matrix of the dermis: flexible structures with dynamic functions, Experimental Dermatology. 20 (2011) 689-695. doi:10.1111/j.16000625.2011.01313.x. 
[23] L.M. Mikesh, L.R. Aramadhaka, C. Moskaluk, P. Zigrino, C. Mauch, J.W. Fox, Proteomic anatomy of human skin, Journal of Proteomics. 84 (2013) 190-200. doi:10.1016/j.jprot.2013.03.019.

[24] A. Didangelos, X. Yin, K. Mandal, A. Saje, A. Smith, Q. Xu, M. Jahangiri, M. Mayr, Extracellular Matrix Composition and Remodeling in Human Abdominal Aortic Aneurysms: A Proteomics Approach, Mol Cell Proteomics. 10 (2011). doi:10.1074/mcp.M111.008128.

[25] G. Burgstaller, B. Oehrle, M. Gerckens, E.S. White, H.B. Schiller, O. Eickelberg, The instructive extracellular matrix of the lung: basic composition and alterations in chronic lung disease, European Respiratory Journal. 50 (2017) 1601805. doi:10.1183/13993003.01805-2016.

[26] B.G. Gálvez, S. Matías-Román, M. Yáñez-Mó, F. Sánchez-Madrid, A.G. Arroyo, ECM regulates MT1-MMP localization with $\beta 1$ or $\alpha \mathrm{v} \beta 3$ integrins at distinct cell compartments modulating its internalization and activity on human endothelial cells, The Journal of Cell Biology. 159 (2002) 509-521. doi:10.1083/jcb.200205026.

[27] M.-H. Lee, S. Atkinson, G. Murphy, Identification of the Extracellular Matrix (ECM) Binding Motifs of Tissue Inhibitor of Metalloproteinases (TIMP)-3 and Effective Transfer to TIMP-1, Journal of Biological Chemistry. 282 (2007) 6887-6898. doi:10.1074/jbc.M610490200.

[28] K.E. Kadler, A. Hill, E.G. Canty-Laird, Collagen fibrillogenesis: fibronectin, integrins, and minor collagens as organizers and nucleators, Current Opinion in Cell Biology. 20 (2008) 495-501. doi:10.1016/j.ceb.2008.06.008.

[29] F. Malfait, S. Symoens, N. Goemans, Y. Gyftodimou, E. Holmberg, V. López-González, G. Mortier, S. Nampoothiri, M. Petersen, A. De Paepe, Helical mutations in type I collagen that affect the processing of the amino-propeptide result in an Osteogenesis Imperfecta/EhlersDanlos Syndrome overlap syndrome, Orphanet Journal of Rare Diseases. 8 (2013) 78. doi:10.1186/1750-1172-8-78.

[30] J. Schalkwijk, M.C. Zweers, P.M. Steijlen, W.B. Dean, G. Taylor, I.M. van Vlijmen, B. van Haren, W.L. Miller, J. Bristow, A Recessive Form of the Ehlers-Danlos Syndrome Caused by Tenascin-X Deficiency, New England Journal of Medicine. 345 (2001) 1167-1175. doi:10.1056/NEJMoa002939.

[31] C.A. Pacak, J.M. Powers, D.B. Cowan, Ultrarapid Purification of Collagen Type I for Tissue Engineering Applications, Tissue Engineering Part C: Methods. 17 (2011) 879-885. doi:10.1089/ten.tec.2010.0720.

[32] M. Asgari, N. Latifi, H.K. Heris, H. Vali, L. Mongeau, In vitro fibrillogenesis of tropocollagen type III in collagen type I affects its relative fibrillar topology and mechanics, Sci Rep. 7 (2017) 1392. doi:10.1038/s41598-017-01476-y.

[33] R. Ross, WOUND HEALING AND COLLAGEN FORMATION: I. Sequential Changes in Components of Guinea Pig Skin Wounds Observed in the Electron Microscope, The Journal of Cell Biology. 11 (1961) 677-700. doi:10.1083/jcb.11.3.677.

[34] B. Brodsky, E.F. Eikenberry, K. Cassidy, An unusual collagen periodicity in skin, Biochimica et Biophysica Acta (BBA) - Protein Structure. 621 (1980) 162-166. doi:10.1016/00052795(80)90072-0.

[35] S.A. Barenberg, F.E. Filisko, P.H. Geil, Ultrastructural deformation of collagen, Connect. Tissue Res. 6 (1978) 25-35.

[36] S.L.M. Dahl, M.E. Vaughn, L.E. Niklason, An Ultrastructural Analysis of Collagen in Tissue Engineered Arteries, Annals of Biomedical Engineering. 35 (2007) 1749-1755. doi:10.1007/s10439-007-9340-8.

[37] A. Ní Annaidh, K. Bruyère, M. Destrade, M.D. Gilchrist, C. Maurini, M. Otténio, G. Saccomandi, Automated Estimation of Collagen Fibre Dispersion in the Dermis and its Contribution to the Anisotropic Behaviour of Skin, Annals of Biomedical Engineering. 40 (2012) 1666-1678. doi:10.1007/s10439-012-0542-3.

[38] T.N. McAllister, M. Maruszewski, S.A. Garrido, W. Wystrychowski, N. Dusserre, A. Marini, K. Zagalski, A. Fiorillo, H. Avila, X. Manglano, J. Antonelli, A. Kocher, M. Zembala, L. Cierpka, L.M. de la Fuente, N. L'heureux, Effectiveness of haemodialysis access with an autologous tissue- 
engineered vascular graft: a multicentre cohort study, Lancet. 373 (2009) 1440-1446. doi:10.1016/S0140-6736(09)60248-8.

[39] W. Wystrychowski, L. Cierpka, K. Zagalski, S. Garrido, N. Dusserre, S. Radochonski, T.N. McAllister, N. L'Heureux, Case Study: First Implantation of a Frozen, Devitalized Tissueengineered Vascular Graft for Urgent Hemodialysis Access, The Journal of Vascular Access. 12 (2011) 67-70. doi:10.5301/JVA.2011.6360.

[40] B.E. Hull, S.E. Sher, S. Rosen, D. Church, E. Bell, Fibroblasts in Isogeneic Skin Equivalents Persist for Long Periods After Grafting, Journal of Investigative Dermatology. 81 (1983) 436-438. doi:10.1111/1523-1747.ep12522605.

[41] S.E. Sher, B.E. Hull, S. Rosen, D. Church, L. Friedman, E. Bell, Acceptance of allogeneic fibroblasts in skin equivalent transplants, Transplantation. 36 (1983) 552-557.

[42] K.G. Donohue, P. Carson, M. Iriondo, L. Zhou, L. Saap, K. Gibson, V. Falanga, Safety and efficacy of a bilayered skin construct in full-thickness surgical wounds, J. Dermatol. 32 (2005) 626-631.

[43] M. Rodríguez, G. Pascual, B. Pérez-Köhler, A. Cifuentes, N. Garcia-Honduvilla, J.M. Bellón, J. Buján, Immune response to the long-term grafting of cryopreserved small-diameter arterial allografts, Histol. Histopathol. 27 (2012) 873-884. doi:10.14670/HH-27.873. 